\title{
Growth and Welfare Effects of World Migration *
}

\author{
Paul Levine \\ Emanuela Lotti \\ University of Surrey \\ University of Surrey \\ Joseph Pearlman \\ Richard Pierse \\ London Metropolitan University \\ University of Surrey
}

October 1, 2009

\begin{abstract}
Using a two-bloc endogenous growth model calibrated to two generic sending and receiving countries of equal size, we assess the growth and welfare impact of world migration flows of different skill compositions. The sending country (East) has a lower total factor productivity and a lower endowment of skilled labour. Migration can induce two growth-enhancing effects: an efficiency effect from the more efficient use of labour in the receiving country (West) and a sectoral reallocation effect from a fall in the host country skilled-unskilled wage rates. Despite growth gains there are both winners (migrants, the representative Western non-migrant household) and losers (the representative Eastern household remaining). Remittances can see the latter group joining the winners.
\end{abstract}

JEL Classification: F22, F43, O41

Keywords: migration, endogenous growth, welfare, immigration surplus, emigration deficit.

\footnotetext{
*The research for this paper was carried with the financial support of the Fifth Framework Programme as part of the project "European Enlargement: The Impact of East-West Migration on Growth and Employment". The authors are grateful for comments from participants at project workshops in Hamburg, Milan, Vienna and Brussels between September 2001 and December 2003, to participants at a seminar at the University of Autonoma, Barcelona, March 2003 and to participants to the EEFS conference in Sofia, May-June 2007.
} 


\section{Contents}

1 Introduction $\quad 1$

2 Related Literature $\quad 3$

3 The Model $\quad 7$

3.1 Consumers and Aggregate Demand . . . . . . . . . . . . . . . . . 9

3.2 Accounting Identities and Eastern Debt . . . . . . . . . . . . . . . . . 11

3.3 The Traditional Sectors _ . . . . . . . . . . . . . . . . . . . 12

3.4 Manufacturing firms . . . . . . . . . . . . . . . . . . . 13

3.5 The Innovative Sector and Knowledge Capital . . . . . . . . . . . . . . . 13

3.6 The Financial Sector . . . . . . . . . . . . . . . . . . . . . 14

3.7 Factor Equilibrium Conditions _. . . . . . . . . . . . . . 15

3.8 Summary of Model f . . . . . . . . . . . . . . . . . . 15

$\begin{array}{lll}4 & \text { The Steady State } & 17\end{array}$

5 Immigration and Welfare $\quad 20$

5.1 Asset Accumulation following Migration . . . . . . . . . . . . . . 20

5.2 Welfare Calculations . . . . . . . . . . . . . . . . . . 22

6 Results 23

6.1 East-West Migration . . . . . . . . . . . . . . . . . . . . . 24

6.1.1 Migration with no Skill Bias . . . . . . . . . . . . . . 24

6.1 .2 Migration with Skill Bias . . . . . . . . . . . . . . . . 24

7 Conclusions and Future Research $\quad 27$

$\begin{array}{ll}\text { A Calibration } & 29\end{array}$

B Terms of trade $\quad 33$

C Stability and Transitional Dynamics (NOT FOR PUBLICATION) $\quad 34$ 


\section{Introduction}

This paper assesses the economic impact of migration flows on both host ("West" from now on) and sending ("East" from now on) regions. Our calibrated model is of the "new-growth, new-trade' genre where long-term growth is driven by innovation in the production of new industries. The East is characterized by a lower total factor productivity in all sectors, a relatively lower endowment of skilled labour and a lower initial capital stock. We examine the impact of migration of different skill compositions. East-West migration induces two potentially growth-enhancing effects: an efficiency effect from the more efficient use of labour in the West and a sectoral reallocation effect arising from the change in the skilledunskilled wage rates. The first effect is studied by examining migration with no skill bias and the second by examining migration of exclusively skilled labour. The case of unskilled migration is analysed as well.

Migration from a poor East to a rich West is a politically contentious subject and welfare analysis that carefully identifies the winners and losers can help to inform this debate. We distinguish the original pre-migration population in the West (the 'native' population), the migrants and those remaining in the East. Each of these groups in turn consist of skilled and unskilled household making six groups in total. The welfare implications of migration for the native population in the host country has received particular attention in the migration literature. In an influential study Borjas (1995) calculates the 'immigration surplus' as the increase in income for this group following immigration. In a one-country study calibrated to the US economy he shows that in the simplest model without endogenous growth, assuming fixed capital and homogeneous labour, a 10\% increase in the workforce results in a very small income-based calculation of the immigration surplus, around $0.1 \%$ in fact. The source of this gain is that immigration lowers the wage rate and since the host population own the capital they benefit overall, though there are losers (workers) as well as winners (owners of capital). Borjas goes on to show that the introduction of skilled and unskilled types of labour can significantly increase the immigration surplus. If the skilled-unskilled labour composition of immigrants differs from that of the native population, a change in the relative wage enables firms to change the composition of their workforce and reach an higher isoquant without increasing the total cost of labour. This relative wage effect increases the Borjas estimation of the immigration 
surplus significantly. If, in addition, it is assumed that skilled labour and capital are complements, then the final estimation of the immigration surplus arising from an increase of $10 \%$ in the US workforce can reach around $1 \%$.

In a static analysis then three factors contribute to the immigration surplus: the fact natives in the West own the capital, the relative wage effect and the complementarity of skilled labour and capital. In our model with endogenous growth, if migration is growth enhancing this provides a further contribution to the immigration surplus. ${ }^{1}$ However the work of Lundborg and Segerstrom (2000) and Lundborg and Segerstrom (2002) in a growth model with homogeneous labour and no capital highlights an important negative contribution from immigration as a result of a reduction in the asset value of equity issued to finance $\mathrm{R} \& \mathrm{D}$. In principle this can dominate resulting in a negative immigration surplus and indeed the results of these authors suggest this may be the case. We can reassess this finding in a richer model of growth that includes physical capital and two types of labour.

As well as assessing the immigration surplus our two-bloc model allows us to estimate the welfare effect on remaining households in the East-the 'emigration surplus'. Our results suggests a negative emigration surplus despite an increase in world growth that benefits East and West. This emigration deficit becomes particularly large in the case of skilled emigration from the East. This deficit arises from two sources: following Chui et al. (2002) the less developed East passes through different stages of development as its levels of total factor productivity and endowment of skilled labour converge to those in the West. In the North-South model of Chui et al. (2002) we allow the South to engage in copying and a combination of copying and innovation of blueprints produced in the North. In this model we assume that Intellectual Property Rights (IPRs) prevail ruling out copying activity. This leaves two stages of development depending on whether there is $R \& D$ activity and high-tech manufacturing in the East. In our pre-migration baseline calibration we assume the East has some R\&D and high-tech manufacturing. Then skilled migration reduces the relative endowment of skilled labour in the East and pushes the structure of the East into that with zero R\&D and only traditional (low-tech)

\footnotetext{
${ }^{1}$ Drinkwater et al. (2007) revisits the Borjas study in an endogenous one-country endogenous growth model along the lines of the two-bloc model of this paper. In a European context, calculations suggest that skilled immigration can result in a utility-based immigration surplus of the order of a $4 \%$ equivalent permanent increase in consumption, but unskilled immigration results in a negative immigration surplus.
} 
good production. Since the high-tech sector is characterized by imperfect competition and positive profits this lowers income in the East. The second source of the emigration deficit arises from a drop in the unskilled-skilled labour wage rates. Since the majority of unskilled workers live in the East in our model, this further adds to the emigration deficit.

Our welfare analysis studies one mechanism that can turn the emigration deficit into a surplus, namely remittances. In Drinkwater et al. (2009) evidence is presented from 20 lower and middle income countries, that include several European countries, indicating that $3.46 \%$ of their GDP is equal to remittances. We examine the impact on the welfare of remaining households in the East of a proportion of the income of migrants (always the overwhelming winners in these studies) being transferred to them in the form of consumption goods.

The rest of the paper is organised as follows. Section 2 provides an overview of the theoretical literature on the effects of migration on growth. We mainly focus on the contributions that links migration and growth driven by $\mathrm{R} \& \mathrm{D}$, but limited space is given to the other strands of the economic growth literature. Section 3 sets out the 'core' model without labour mobility. Section 4 sets out the balanced-growth steady state of the dynamic model. Section 5 provides the welfare calculation for migrants, remaining residents in the East and indigenous households in the West taking into account ownership of assets. Each of these groups is divided into skilled and unskilled households giving six groups in total. Section 6 sets out the numerical results and section 7 provides conclusions and some suggestions for future developments of the model.

\section{Related Literature}

Many contributions to the literature on the effects of labour mobility on growth focus on the impact of migration either on the source or on the receiving country. As pointed out in Lundborg and Segerstrom (2002), the studies of labour migration in a one-country endogenous growth framework have a series of limitations. The advantage of simplicity is offset by a lack in reality. In the real world countries are connected by trade in goods. Another drawback of the one-country endogenous growth literature is that it can not take into account the incentives for labour mobility. Finally, migration is quite likely to have a long lasting impact not only on the host country, but also on the source country. The 
latter effects can be positive or negative depending on the interplay between the effects of growth, remittances and the brain drain.

A vast literature has emerged since the 1980's which focus on the role of consumption and saving decisions of households, the investment decisions of firms and public policy on long-term growth. The impact of migration and in general of skill composition on longterm growth is analyzed within models where growth is driven by physical and human capital accumulation or, following Romer (1990) and Grossman and Helpman (2001), through the discovery of new goods and new processes (R\&D). In the latter, the impact of the skill level on growth is far more complex than the one described in the literature where growth is driven by capital accumulation. It is based on the incentives to engage in $R \& D$ activities and on the possibility to use skilled migrants in a more efficient way.

The following table synthesizes few studies on the impact of migration on growth:

\begin{tabular}{|c|c|c|}
\hline & One country & Two countries \\
\hline Human \& Physical Capital & Ben-Gad (2003) & Walz (1995) \\
Research \& Development & Drinkwater et al. (2007) & LS, Bretscher (2001) \\
\hline
\end{tabular}

\section{Table 1. Examples of Studies Linking Growth and Migration}

As an example of the literature based on human capital accumulation, Walz (1995) uses a 2-bloc endogenous growth model to address the effects of migration on both source and host countries. The central idea of the work is that migration affects the growth rate of the economies by altering the composition of the labour force in each country. Migration can be beneficial for individuals in both countries and if migration increases the overall growth rate, the positive dynamic effects offset any negative static effects ${ }^{2}$. In contrast with Walz (1995), Ben-Gad (2003) considers a closed economy that opens only to include migration. They extend Lucas (1988) model by introducing a labour-leisure choice. The introduction of human capital externalities interacts with the analysis on the skill composition of the migrants. The author shows that in the case of a modest intertemporal elasticity of labour supply and returns to scale between 1 and 1.1, immigration lowers the growth rate in the host economy.

Our paper is close to the literature that looks at the impact of migration in a 2country endogenous growth framework where technical change is driven by $R \& D(R \& D$

\footnotetext{
${ }^{2}$ The result depends on the initial specialization pattern.
} 
and two countries in the table). The effects of migration from the East to the West is examined by Lundborg and Segerstrom $(2000,2002)$ in a two-country quality ladders model of economic growth and by Bretscher (2001) in an expansion-in-varieties model. While Lundborg and Segerstrom (2002) deals with the effects of international migration between developed countries on growth, Lundborg and Segerstrom (2000) investigates the potential impact of mass migration from middle-wage to high wage countries (e.g. from former communist countries to actual members of the EU). In particular, in this second paper the authors look at the desirability of large immigration quotas for both sending and receiving countries. Migration generates static and dynamic effects from changes in wages and from higher growth. The dynamic effects are in general positive but not sufficient to compensate the negative level effects which generates losers among Northern workers and Southern capitalists ${ }^{3}$. Northern capitalists are not particularly affected while migrants and Southern workers are the clear winner in the analysis. The results of a negative impact of migration on the welfare of natives contrasts with the findings obtained through static models of migration as in Borjas (1995) and suggests that the attitude of natives towards migrants can be associated with economic fears . An important feature of Lundborg and Segerstrom (2000) is the evaluation of the model using computer simulations. This is due to the difficulties generated by the assumption of two asymmetric countries. We retain this feature in our work by relating the model to generic host and receiving economies and assuming asymmetries between the two blocs. In contrast to our work, Lundborg and Segerstrom (2000) assume homogeneous workers in a one-sector economy.

Our work is also close to Bretscher (2001) which examines the impact of the supply of unskilled and skilled migration on the growth rate in open economies. By assuming a specific utility function, the author shows analytically that there is an unambiguously positive relationship between growth and an increase in the proportion of skilled labour. Similar to our work, Bretschger assumes that the ranking of skilled labour intensiveness in the sectors is traditional, manufacturing and R\&D. In a version of this model, the author looks at an expansion-in-varieties in the production sector which explicitly considers the impact of migration on the incentives to generate new knowledge capital. In this case unskilled migration has clearly negative effects on the growth rate, while migration of

\footnotetext{
${ }^{3}$ This result is driven by the assumption that the difference in R\&D productivity in the two countries is not large.
} 
high skilled has again unambiguously positive effects on the growth rate. In contrast with our work, Bretscher (2001) does not assume asymmetries between the two countries and growth depends only on the sectoral reallocation of resources. Bretschger and Steger (2004) shows that migration depends on two effects: the scale effect and the sectoral reallocation effect and the two could go in different directions. In particular, while the scale effect is always positive, the sectoral reallocation effect is ambiguous in sign depending on the elasticity of substitution between low and high skilled workers. In our model, the increase in labour supply in the West induces both an efficiency effect and a sectoral reallocation effect.

The importance of the skill composition of migrants on growth is also emphasised by Drinkwater et al. (2007). The work, through simulations on an expanding in varieties model with physical capital, general CES utility functions and Cobb-Douglas production technology confirms, in a closed economy framework, most of the analytical results in Bretschger. The main result of this model is that growth effects on the Immigration Surplus come to dominate the purely static effects, but they are not sufficient to eliminate the emergence of losers among natives competing with immigrants in the labour market. Here we review the findings in Drinkwater et al. (2007) for open economies and examine the impact of changes in labour supply on both host and source countries.

Finally, we take into account the impact of immigration on the terms of trade of the host economy and show that immigration negatively affects its terms of trade. Davis and Weinstein (2002) claim that immigration has a negative impact on native welfare through worsening of the terms of trade of the home economy. The authors adopt a standard Ricardian model amended to allow migration to a country (i.e. US or the West) which is technologically superior in all factors. The main idea of their work is the following: when the technologically superior country opens to trade it initially enjoys monopoly power. Immigration then amounts to an erosion of this power. World income increases, but natives always loose. Felbermayr and Kohler (2007) explain how very often labour economists focuses their analysis of migration on the complementarity relationship between immigrants and some domestic factors generating the so-called Immigration Surplus, leaving goods prices exogenous. Felbermayr and Kohler (2007) points to the need to analyse the complementarity effect together with the Davis-Weinstein (D-W) negative terms of trade 
effect. In our paper, the native welfare effect of immigration is the result of various opposing forces where technological complementarities and the terms of trade effects are only part of a wider picture. In our simulations, we can see that high-skilled migration has a negative impact on the terms of trade of the host economy as in Davis and Weinstein (2002), but this is more than offset by the positive effect on endogenous growth. ${ }^{4}$

A series of papers studies the impact of EU Enlargement on the old and new members as in D'Auria and Morrow (2008) and Kahanec et al. (2009). Our model refers to EU members when choosing some of the parameters used in the calibration, but we mainly look at a generic "North" (West) and a generic "South" (East) when we assess the impact of migration on growth and welfare.

\section{The Model}

In each bloc East $(E)$ and West $(W)$, in the absence of specialization there are four sectors: a high-technology manufacturing sector, $m$, produces an expanding variety of differentiated goods; a traditional traded sector, $y$, produces a single traded homogeneous good (e.g., food, steel); a traditional non-traded sector, $z$, produces another homogeneous good (e.g., construction, services) and an $\mathrm{R} \& \mathrm{D}$ innovative sector, $i$, produces blueprints for new manufactured goods. Sectors $\mathrm{m}, \mathrm{y}$ and $\mathrm{z}$ use four factor inputs consisting of skilled labour $H^{b}$, and unskilled labour $L^{b}, b=E, W$ in the aggregate, and physical capital consisting of inputs from the two traditional sectors. The ranking of unskilledskilled labour intensiveness is: $\mathrm{z}, \mathrm{y}, \mathrm{m}$ and $\mathrm{i}$. The assumed market structures for outputs are competitive for the traditional and R\&D sectors and monopolistic for manufacturing. Labour markets are assumed to clear and there are no free public services. In the basic model there is no labour mobility between East and West. Migration between these blocs is then considered in a subsequent section of the paper.

Asymmetries between East and West are a central aspect of this study. On the demand side in our analysis we allow for the possibility that parameters (such as the discount rate) defining consumer preferences differ between the two regions. Following Parente and Prescott (2000) we assume that both East and West have access to the same common

\footnotetext{
${ }^{4}$ We present the result for high skilled migration, but a similar conclusion applies to the case of unbiased migration as well.
} 
technologies, but the ability of firms to avail themselves of the best technology differ in the two blocs, leading to different total factor productivities. Estimates from Hall and Jones (1999) of total factor productivities for the US and some typical East and West European economies are given in table 1 below. Since our focus is on long-run growth, the question arises as to whether such large TFP differences will persist for long in the sending economies. Estimates of TFP growth and labour productivity for Eastern and Western Germany in the 1990s from Burda and Hunt (2001) show that in the first half of the decade convergence was rapid, but in the second half it slowed down considerably leaving Eastern labour productivity almost frozen at around two-thirds of that in the West. This suggests that for the specific case of transitional economies we may expect some rapid convergence at first, but that some significant East-West TFP productivity difference will persist for some considerable time. This is what we assume in our simulations where the TFP in the East stays always below the TFP in the West (two-thirds), though we only examine the steady-state ${ }^{5}$. The remaining differences between East and West are the factor endowments of skilled and unskilled labour and initial capital stocks. ${ }^{6}$

\begin{tabular}{|c|c|c|}
\hline Country & $\frac{Y}{L}$ & TFP \\
\hline USA & 1.00 & 1.00 \\
Italy & 0.834 & 1.14 \\
W.Germany & 1.118 & 0.94 \\
France & 0.818 & 1.09 \\
UK & 0.727 & 1.01 \\
\hline Cyprus & 0.446 & 0.737 \\
Malta & 0.463 & 0.812 \\
Hungary & 0.307 & 0.424 \\
Czech & 0.211 & 0.369 \\
Poland & 0.238 & 0.363 \\
\hline
\end{tabular}

Table 2. Labour Productivity and TFP Differences between Countries (Hall and Jones, 1999)

\footnotetext{
${ }^{5}$ An additional appendix $\mathrm{C}$ available from the authors contains the dynamic analysis of the model

${ }^{6}$ The latter however are irrelevant for the steady state results.
} 


\subsection{Consumers and Aggregate Demand}

In blocs $b=E, W$, consumers consist of two representative households. Types $l=L, H$, supply fixed quantities of labour to the labour market and maximises an intertemporal utility function,

$$
U_{l}^{b}(t)=\int_{0}^{\infty} e^{-\rho^{b}(\tau-t)}\left\{\frac{\left[\left(C_{m l}^{b}\right)^{\theta_{m}^{b}}\left(C_{y l}^{b}\right)^{\theta_{y}^{b}}\left(C_{z l}^{b}\right)^{\theta_{z}^{b}}\right]^{1-1 / \sigma}-1}{1-1 / \sigma^{b}}\right\} d \tau ; \quad \sum_{i=m, y, z} \theta_{i}^{b}=1, \sigma^{b} \neq 1
$$

where $\rho^{b}$ is the subjective discount rate, $\sigma<1$ is the intertemporal elasticity of substitution, $C_{y l}^{b}$ and $C_{z l}^{b}$ are total consumption of the traditional traded and non-traded goods respectively by type $l$; and $C_{m l}^{b}$, an index of consumed manufacturing goods by households of type $l$, takes the form

$$
C_{m l}^{b}=\left[\int_{0}^{n}\left(x_{l j}^{b}\right)^{\alpha} d j\right]^{1 / \alpha} ; \quad \alpha \in(0,1)
$$

due to Dixit-Stiglitz, where $n$ is the total number of varieties available, $\alpha$ is a taste parameter and $x_{j l}^{b}$ is consumption of variety $j$ by type $l$ in bloc $b .^{7}$

The consumers' optimization problem consists of two stages. Let $p_{m j}$ be the price of manufactured variety $j$ and $p_{y}, p_{z}^{b}, b=E, W$ be the prices of the traded and nontraded traditional goods. Then the first stage is the current period maximization of $\left(C_{m l}^{b}\right)^{\theta_{m}}\left(C_{y l}^{b}\right)^{\theta_{y}}\left(C_{z l}^{b}\right)^{\theta_{z}}$ over the varieties given total nominal household expenditure for each group of workers, $C_{l}^{b}=\int_{0}^{n}\left[p_{m j} x_{j l}^{b}\right] d j+p_{y} C_{y l}^{b}+p_{z}^{b} C_{z l}^{b}$. This is a standard problem which yields demands

$$
C_{y l}^{b}=\theta_{y}^{b} \frac{C_{l}^{b}}{p_{y}} ; \quad C_{z l}^{b}=\theta_{z}^{b} \frac{C_{l}^{b}}{p_{z}^{b}} ; \quad x_{j l}^{b}=\frac{\theta_{m}^{b} C_{l}^{b} p_{m j}^{-\varepsilon}}{\int_{0}^{n} p_{m j^{\prime}}^{1-\varepsilon} d j^{\prime}} ; \quad l=L, H, ; b=E, W
$$

where $\varepsilon=1 /(1-\alpha)>1$ is the elasticity of substitution. Hence the total nominal consumption of manufactured goods in bloc b by households of type 1 is given by

$$
\int_{0}^{n} p_{m j} x_{j l}^{b} d j=\theta_{m}^{b} C_{l}^{b}=P_{m} C_{m l}^{b}
$$

where $C_{m l}^{b}$ is real consumption and

$$
P_{m}=\left[\int_{0}^{n} p_{m j}^{1-\epsilon}\right]^{\frac{1}{1-\epsilon}}
$$

\footnotetext{
${ }^{7}$ Notice the elasticity $\epsilon=1 /(1-\alpha)$ is assumed to be equal across all varieties wherever they are produced.
} 
is the price index for manufacturing. Finally the profit-maximizing choice of output by the firm producing variety $j$ requires the total world demand for the variety $j$ given by

$$
x_{j}=\sum_{b=E, W}\left(x_{L j}^{b}+x_{H j}^{b}\right)=\frac{\left[\sum_{b=E, W} \theta_{m}^{b} C^{b}\right] p_{j}^{-\varepsilon}}{\int_{0}^{n} p_{j^{\prime}}^{1-\varepsilon} d j^{\prime}}
$$

where $C^{b}=C_{L}^{b}+C_{H}^{b}$ is total households' nominal expenditure in bloc b.

The second stage of the consumers' problem is intertemporal. Net assets, $A_{l}^{b}$, held by households of type $l$ consist of an equity stake in new blueprints, domestic physical capital in all sectors and claims on domestic and foreign residents. Arbitrage in capital markets within each bloc ensures equality on the return $r^{b}$ from these assets. This implies budget constraints for the groups $l=L, H$ of the form:

$$
\dot{A}_{L}^{b}=r^{b} A_{L}^{b}+w_{L}^{b} L^{b}-T_{L}^{b}-C_{L}^{b} ; \quad \dot{A}_{H}^{b}=r^{b} A_{H}^{b}+w_{H}^{b} H^{b}-T_{H}^{b}-C_{H}^{b},
$$

where $\mathbf{w}^{\mathbf{b}}=\left[w_{L}^{b}, w_{H}^{b}\right]$ are the wage rates and $\left[T_{L}^{b}, T_{H}^{b}\right]$ are non-distortionary taxes paid by the two groups. Maximizing (1) subject to (2), (3) and (7) gives another standard result:

$$
\dot{C}_{l}^{b} / C_{l}^{b}-\dot{P}^{b} / P^{b}=\sigma^{b}\left(r^{b}-\dot{P}^{b} / P^{b}-\rho^{b}\right) ; l=L, H
$$

where

$$
P^{b}=\left(P_{m}\right)^{\theta_{m}^{b}} p_{y}^{\theta_{y}^{b}}\left(p_{z}^{b}\right)^{\theta_{z}^{b}}
$$

is the price index for total consumption in bloc b. Hence aggregating over the two types of household we have

$$
\dot{C}^{b} / C^{b}-\dot{P}^{b} / P^{b}=\sigma^{b}\left(r^{b}-\dot{P}^{b} / P^{b}-\rho^{b}\right)
$$

The budget constraint for aggregate net assets wealth is,

$$
\dot{A}^{b}=r^{b} A^{b}+w_{L}^{b} L^{b}+w_{H}^{b} H^{b}-C^{b},
$$

In each region manufacturing firms have identical costs and all firms, East or West, face an identical demand given by (6). Hence $p_{j}=p^{W}, j=1,2, \cdots, n^{W}$ and $p_{j}=p^{E}, j=$ $n^{W}+1, n^{W}+2, \cdots, n$ where $n=n^{W}+n^{E}$. Then from (5) we now have that $P_{m}=$ $\left[n^{W}\left(p^{W}\right)^{1-\epsilon}+n^{E}\left(p^{E}\right)^{1-\epsilon}\right]^{\frac{1}{1-\epsilon}}$. We can now write aggregate assets in region $\mathrm{b}$ as:

$$
A^{b}=A_{L}^{b}+A_{H}^{b}=n^{b} v^{b}+p_{y} K_{y}^{b}+p_{z}^{b} K_{z}^{b}+F^{b}
$$

where $n^{b}$ varieties with stock market value $v^{b}$ are produced in bloc b and $K_{y}^{b}$ and $K_{z}^{b}$ are aggregate levels of physical capital created from the two traditional sectors and $F^{b}$ are net claims of bloc b on residents in the other bloc (a negative value implies a liability). 


\subsection{Accounting Identities and Eastern Debt}

Let $B_{j}^{b} ; j=y, m$ denote the trade balance in traded sector $j$. Then the accounting identities are:

$$
\begin{aligned}
p_{y} Y^{b} & =p_{y}\left(C_{y}^{b}+\dot{K}_{y}^{b}+\delta_{y} K_{y}^{b}\right)+B_{y}^{b} \\
Z^{b} & =C_{z}^{b}+\dot{K}_{z}^{b}+\delta_{z} K_{z}^{b} \\
p_{m}^{b} n^{b} x^{b} & =P_{m} C_{m}^{b}+B_{m}^{b}
\end{aligned}
$$

where $\delta_{y}, \delta_{z}$ are the depreciation rates for the three types of capital. If financial capital is mobile, $r^{E}=r^{W}=r$, say, and foreign assets held by each bloc accumulate according to:

$$
\dot{F}^{b}=r F^{b}+B_{y}^{b}+B_{m}^{b}
$$

and $F^{W}=-F^{E}$, in this two-bloc world. From (16) this is equivalent to the world trade balance condition

$$
B_{y}^{W}+B_{m}^{W}+B_{y}^{E}+B_{m}^{E}=0
$$

However open-economy models with capital mobility of this genre have some implausible properties, discussed in Barro and Sala-I-Martin (1995), chapter 3. One way of resolving this difficulty is to assume that the bloc that borrows is credit-constrained and can only borrow up to its holdings of other assets; i.e., if it is the East that borrows then liabilities $F^{W}$ are constrained by $A^{E} \geq 0$. With credit constraints interest rates $r^{W}$ and $r^{W}$ can diverge. In the complete absence of capital mobility, interest rates can diverge and the trade must balance implying

$$
B_{y}^{b}+B_{m}^{b}=0
$$

We can set up the model to incorporate capital immobility as a special case of constrained mobility as follows. The credit constraint takes the form:

$$
F^{W} \leq \phi\left(n^{E} v^{E}+p_{y} K_{y}^{E}+p_{z} K_{z}^{E}\right)=\phi a^{E}
$$

say, where $\phi \in[0,1]$ is the maximum proportion of Eastern assets, $a^{E}$, owned by Western households. Then (16) applies and $r^{W}=r^{E}=r$ iff $F^{W}<\phi a^{E}$. Otherwise the credit constraint binds, $r^{W} \neq r^{E}$ necessarily and (16) is replaced with

$$
\phi \dot{a}^{E}=r^{W} \phi a^{E}+B_{y}^{W}+B_{m}^{W}
$$




\subsection{The Traditional Sectors}

Turning to the supply side, since the traditional sectors are perfectly competitive, the price is equal to the marginal cost. If both regions produce the traded traditional good, global price equalization then gives the following equality

$$
p_{y}=\Gamma_{y}^{E}\left(\mathbf{w}^{\mathbf{E}}, \mathbf{R}^{\mathbf{E}}\right)=\Gamma_{y}^{w}\left(\mathbf{w}^{\mathbf{W}}, \mathbf{R}^{\mathbf{W}}\right) .
$$

where $\Gamma_{y}^{b}(\cdot)$ is a cost function and $\mathbf{R}^{\mathbf{b}}=\left[\mathbf{R}_{\mathbf{y}}^{\mathbf{b}}, \mathbf{R}_{\mathbf{z}}^{\mathbf{b}}\right]$ are the net costs (rental prices) of the two types of physical capital. Equating the returns on capital to $r^{b}$ we have

$$
R_{j}^{b}=p_{j}^{b}\left[r^{b}+\delta_{j}-\frac{\dot{p}_{j}^{b}}{p_{j}^{b}}\right] ; j=y, z
$$

In (21), unit cost functions $\Gamma_{y}^{b}\left(\mathbf{w}^{\mathbf{b}}, \mathbf{R}^{\mathbf{b}}\right), b=E, W$, for the traded traditional sector and the corresponding unit factor requirements are derived from the following, CES production function

$$
\left.Y^{b}=T_{y}^{b}\left[\left[\gamma_{1 y} L_{y}^{\mu_{y}}+\gamma_{2 y} H_{y}^{\mu_{y}}\right]^{\frac{\eta_{y}}{\mu_{y}}}+\left[\gamma_{3 y} K_{y y}^{\xi_{y}}+\gamma_{4 y} K_{z y}^{\xi_{y}}\right]^{\frac{\eta_{y}}{\xi_{y}}}\right]\right]^{\frac{1}{\eta_{y}}} ; \sum_{j=1}^{4} \gamma_{j y}=1
$$

for factor inputs $\left[L_{y}, H_{y}, K_{y y}, K_{z y}\right]$ into the y-sector. In $(23), \sigma_{\mu_{y}}=1 /\left(1-\mu_{y}\right)$ is the elasticity of substitution between skilled and unskilled labour, $\sigma_{\xi_{y}}=1 /\left(1-\xi_{y}\right)$ is the elasticity of substitution between the two types of physical capital and $\sigma_{\eta_{y}}=1 /\left(1-\eta_{y}\right)$ is the elasticity of substitution between labour of either type with physical capital of either type. ${ }^{8}$

We assume identical technology is available in both blocs apart from the total factor productivity, $T_{y}^{b}$, which can differ. We assume that the East is inefficient relative to the West in all sectors. If this inefficiency is uniform across sectors, with our constant returns to scale production functions this can be interpreted the quality of skilled, unskilled labour and physical capital in the West being uniformly higher than in the East (in addition to the proportion of skilled workers being higher). Alternatively (or in addition) the inefficiency could be caused by barriers to innovation as in Parente and Prescott(2000) in which case it need not be uniform across sectors.

\footnotetext{
${ }^{8}$ An alternative specification for the CES production function assumes a common rate of substitution between unskilled labour on the one hand, and skilled labour and all types of physical capital on the other; i.e., $Y^{b}=T_{y}^{b}\left[\left[\gamma_{1 y} L_{y}^{\eta_{y}}+\left[\gamma_{2 y} H_{y}^{\xi_{y}}+\gamma_{3 y} K_{y y}^{\xi_{y}}+\gamma_{4 y} K_{z y}^{\xi_{y}}\right]^{\frac{\eta_{y}}{\xi_{y}}}\right]\right]^{\frac{1}{\eta_{y}}}$. Then $\eta_{y}>0$ and $\xi_{y}<0$ captures the empirical possibility that skilled labour and physical capital are complements (Hammermesh (1993)).
} 
For the non-traded traditional sectors prices in each bloc can differ and (21) becomes

$$
p_{z}^{b}=\Gamma_{z}^{b}\left(\mathbf{w}^{\mathbf{b}}, \mathbf{R}^{\mathbf{b}}\right) ; b=E, W
$$

where unit cost functions $\Gamma_{z}^{b}\left(\mathbf{w}^{\mathbf{b}}, \mathbf{R}^{\mathbf{b}}\right), b=E, W$ are derived from an analogous CES production function

$$
\left.Z^{b}=T_{z}^{b}\left[\left[\gamma_{1 z} L_{z}^{\mu_{z}}+\gamma_{2 z} H_{z}^{\mu_{z}}\right]^{\frac{\eta_{z}}{\mu_{z}}}+\left[\gamma_{3 z} K_{y z}^{\xi_{z}}+\gamma_{4 z} K_{z z}^{\xi_{z}}\right]^{\frac{\eta_{z}}{\xi_{z}}}\right]\right]^{\frac{1}{\eta_{z}}} ; \sum_{j=1}^{4} \gamma_{j z}=1
$$

for factor inputs $\left[L_{z}, H_{z}, K_{y z}, K_{z z}, K_{m z}\right]$ into the z-sector.

\subsection{Manufacturing firms}

Given factor inputs $\left[L_{m}, H_{m}, K_{y m}, K_{z m}\right]$, production in the manufacturing sector producing variety $j$ is given by a CES production function analogous to (23)

$$
\left.x_{j}^{b}=T_{m}^{b}\left[\left[\gamma_{1 m} L_{m}^{\mu_{m}}+\gamma_{2 m} H_{m}^{\mu_{m}}\right]^{\frac{\eta_{m}}{\mu_{m}}}+\left[\gamma_{3 m} K_{y m}^{\xi_{m}}+\gamma_{4 m} K_{z m}^{\xi_{m}}\right]^{\frac{\eta_{m}}{\xi_{m}}}\right]\right]^{\frac{1}{\eta_{m}}} ; \sum_{j=1}^{4} \gamma_{j m}=1
$$

from which the cost functions $\Gamma_{m}^{b}\left(\mathbf{w}^{\mathbf{b}}, \mathbf{R}^{\mathbf{b}}\right)$ are derived as before.

The manufacturing firm in either bloc producing variety $j$ at price $p_{j}$ where $j \in[0, n]$ maximises profits, $\pi_{j}=\left(p_{j}^{b}-\Gamma_{m}^{b}\right) x_{j}^{b}$ with $x_{j}^{b}$ given by (6). For identical firms in each bloc, this yields equilibrium price, output, profits and manufacturing price index:

$$
\begin{aligned}
p^{b} & =\frac{\Gamma_{m}^{b}}{\alpha} \\
x^{b} & =\frac{\theta_{m} C\left(p^{b}\right)^{-\epsilon}}{P_{m}^{1-\epsilon}} \\
\pi^{b} & =(1-\alpha) p^{b} x^{b} \\
P_{m} & =\left[n^{E}\left(p^{E}\right)^{1-\epsilon}+n^{W}\left(p^{W}\right)^{1-\epsilon}\right]^{\frac{1}{1-\epsilon}}
\end{aligned}
$$

Notice that since $\epsilon>1, P_{m}$ is a decreasing function of the number of varieties, $n=n^{E}+n^{W}$.

\subsection{The Innovative Sector and Knowledge Capital}

The innovative R\&D sector employs mainly labour and the rate of production of new goods invented in this sector is given by the production function

$$
\dot{n}^{b}=T_{i}^{b} \Lambda\left[\left[\gamma_{1 i} L_{i}^{\mu_{i}}+\gamma_{2 i} H_{i}^{\mu_{i}}\right]^{\frac{\eta_{i}}{\mu_{i}}}+\left[\gamma_{3 i} K_{y i}^{\xi_{i}}+\gamma_{4 i} K_{z i}^{\xi_{i}}\right]\right]^{\frac{1}{\eta_{i}}} ; \sum_{j=1}^{4} \gamma_{j i}=1
$$


where $\Lambda$ is knowledge capital. Our treatment of knowledge capital differs from much of the literature in that we adopt a formulation that does not lead to the empirically troublesome conclusion that growth increases with population size. The basic idea is that a new blueprint emerging in the R\&D sector contains new ideas and information useful to future generations of innovations but these diffuse gradually in time and through the population. Let $L^{E}+H^{E}+L^{W}+H^{W}=N$ say, be the total world's working population. In fact, later we normalise $N=1$. Let $n=n^{E}+n^{W}$ be the total number of varieties in the world. Then knowledge capital $\Lambda$ is defined by

$$
\Lambda=\frac{n}{N}
$$

i.e., knowledge capital depends on the density of varieties in the population and not on the absolute number. This small change in the usual formulation (for example adopted in Grossman and Helpman (2001)) removes the world population size effect on growth. Notice also that knowledge capital is independent of the distribution of populations between East and West and is therefore unaffected by migration.

\subsection{The Financial Sector}

Let the stock market value of the typical $\mathrm{R} \& \mathrm{D}$ firm in bloc b be denoted by $v^{b}$. A new blueprint $\operatorname{costs} \Gamma_{i}\left(\mathbf{w}^{\mathbf{b}}, \mathbf{R}^{\mathbf{b}}\right) / \Lambda$, and the NPV rule requires this to be equated with $v^{b}$, giving

$$
v^{b}=\frac{\Gamma_{i}\left(\mathbf{w}^{\mathbf{b}}, \mathbf{R}^{\mathbf{b}}\right)}{\Lambda}
$$

The no-arbitrage condition is

$$
\frac{\pi^{b}}{v^{b}}+\frac{\dot{v}^{b}}{v^{b}}=r^{b}
$$

the left hand side is the total rate of return to equity holders (dividend plus capital gains) and $r^{b}$ denotes the interest rate on riskless loans between households. If

$$
\frac{\pi^{b}}{v^{b}}+\frac{\dot{v}^{b}}{v^{b}}<r^{b}
$$

then no innovative goods are created in bloc b. 


\subsection{Factor Equilibrium Conditions}

If all labour markets clear labour market equilibrium condition for each type of labour are

$$
\begin{aligned}
\frac{a_{L i}^{b}}{\Lambda} \dot{n}^{b}+a_{L m}^{b} n^{b} x^{b}+a_{L y}^{b} Y^{b}+a_{L z}^{b} Z^{b} & =L^{b} \\
\frac{a_{H i}}{\Lambda} \dot{n}^{b}+a_{H m}^{b} n^{b} x^{b}+a_{H y}^{b} Y^{b}+a_{H z}^{b} Z^{b} & =H^{b}
\end{aligned}
$$

The model is closed with the equilibrium conditions for the remaining factors, $K_{y}$ and $K_{z}$.

$$
\begin{aligned}
& \frac{a_{K_{y} i}^{b}}{\Lambda} \dot{n}^{b}+a_{K_{y} m}^{b} n^{b} x^{b}+a_{K_{y} y}^{b} Y^{b}+a_{K_{y} z}^{b} Z^{b}=K_{y}{ }^{b} \\
& \frac{a_{K_{z} i}}{\Lambda} \dot{n}^{b}+a_{K_{z} m}^{b} n^{b} x^{b}+a_{K_{z} y}^{b} Y^{b}+a_{K_{z} z}^{b} Z^{b}=K_{z}^{b}
\end{aligned}
$$

\subsection{Summary of Model}

\section{Consumption Demand}

$$
\begin{aligned}
C_{z}^{b} & =\frac{\theta_{z}^{b} C^{b}}{p_{z}^{b}} \\
C_{y}^{b} & =\frac{\theta_{y}^{b} C^{b}}{p_{y}} \\
C_{m}^{b} & =\frac{\theta_{m}^{b} C^{b}}{P_{m}} \\
x^{b} & =\frac{\left(\theta_{m}^{E} C^{E}+\theta_{m}^{W} C^{W}\right)\left(p_{m}^{b}\right)^{-\epsilon}}{P_{m}^{1-\epsilon}} \\
\frac{\dot{C}^{b}}{C^{b}} & =\left(1-\sigma^{b}\right) \frac{\dot{P}^{b}}{P^{b}}+\sigma^{b}\left(r^{b}-\rho^{b}\right)
\end{aligned}
$$

Aggregate Demand

$$
\begin{aligned}
p_{y} Y^{b} & =p_{y}\left(C_{y}^{b}+\dot{K}_{y}^{b}+\delta_{y} K_{y}^{b}\right)+B_{y}^{b} \\
Z^{b} & =C_{z}^{b}+\dot{K}_{z}^{b}+\delta_{z} K_{z}^{b}+G^{b} \\
p_{m}^{b} n^{b} x^{b} & =P_{m} C_{m}^{b}+B_{m}^{b}
\end{aligned}
$$

Assets

$$
\begin{aligned}
& A^{b}=n^{b} v^{b}+p_{y} K_{y}^{b}+p_{z}^{b} K_{z}^{b}+F^{b}=a^{b}+F^{b} \\
& \dot{A}^{b}=r^{b} A^{b}+w_{L}^{b} L^{b}+w_{H}^{b} H^{b}-\frac{n^{b} \Gamma_{i}^{b} s^{b}}{\Lambda}-C^{b}
\end{aligned}
$$

Eastern Debt and World Balanced Trade Condition

$$
\text { if } \begin{aligned}
F^{W}<\phi a^{e} \text { then } r^{W} & =r^{E}=r \text { and } \dot{F}^{W}=r^{W} F^{W}+B_{y}^{W}+B_{m}^{W} \\
\text { otherwise } r^{W} & \neq r^{E} \text { and } \phi \dot{a}^{E}=r^{W} \phi a^{E}+B_{y}^{W}+B_{m}^{W}
\end{aligned}
$$




$$
B_{y}^{E}+B_{m}^{E}+B_{y}^{W}+B_{m}^{W}=0
$$

Capital Returns

$$
\begin{aligned}
& R_{y}^{b}=p_{y}\left[r^{b}+\delta_{y}-\frac{\dot{p}_{y}}{p_{y}}\right] \\
& R_{z}^{b}=p_{z}^{b}\left[r^{b}+\delta_{z}-\frac{\dot{p}_{z}^{b}}{p_{z}^{b}}\right]
\end{aligned}
$$

Traditional Sectors

$$
\begin{aligned}
& p_{z}^{b}=\Gamma_{z}^{b}\left(\mathbf{w}^{\mathbf{b}}, \mathbf{R}^{\mathbf{b}}\right) \\
& p_{y}=\Gamma_{y}^{b}\left(\mathbf{w}^{\mathbf{b}}, \mathbf{R}^{\mathbf{b}}\right)
\end{aligned}
$$

Manufacturing Sector

$$
\begin{aligned}
p_{m}^{b} & =\frac{\Gamma_{m}\left(\mathbf{w}^{\mathbf{b}}, \mathbf{R}^{\mathbf{b}}\right)}{\alpha} \\
\pi^{b} & =(1-\alpha) p_{m}^{b} x^{b}
\end{aligned}
$$

Aggregate Price Indices

$$
\begin{aligned}
P_{m} & =\left[n^{E}\left(p_{m}^{E}\right)^{1-\epsilon}+n^{W}\left(p_{m}^{W}\right)^{1-\epsilon}\right]^{\frac{1}{1-\epsilon}} \\
P^{b} & =P_{m}^{\theta_{m}^{b}} p_{y}^{\theta_{y}^{b}}\left(p_{z}^{b}\right)^{\theta_{z}^{b}}
\end{aligned}
$$

Financial Sector

$$
\begin{aligned}
v^{b} & =\frac{\Gamma_{i}\left(\mathbf{w}^{\mathbf{b}}, \mathbf{R}^{\mathbf{b}}\right)}{\Lambda} \\
\frac{\pi^{b}}{v^{b}}+\frac{\dot{v}^{b}}{v^{b}} & \geq r^{b}
\end{aligned}
$$

World Knowledge Capital

$$
\Lambda=\frac{n^{E}+n^{W}}{N}
$$

Factor Equilibrium

$$
\begin{aligned}
\frac{a_{L i}^{b}}{\Lambda} \dot{n}^{b}+a_{L m}^{b} n^{b} x^{b}+a_{L y}^{b} Y^{b}+a_{L z}^{b} Z^{b} & =L^{b} \\
\frac{a_{H i}}{\Lambda} \dot{n}^{b}+a_{H m}^{b} n^{b} x^{b}+a_{H y}^{b} Y^{b}+a_{H z}^{b} Z^{b} & =H^{b} \\
\frac{a_{K_{y} i}^{b}}{\Lambda} \dot{n}^{b}+a_{K_{y} m}^{b} n^{b} x^{b}+a_{K_{y} y}^{b} Y^{b}+a_{K_{y} z}^{b} Z^{b} & =K_{y}{ }^{b} \\
\frac{a_{K_{z} i}}{\Lambda} \dot{n}^{b}+a_{K_{z} m}^{b} n^{b} x^{b}+a_{K_{z} y}^{b} Y^{b}+a_{K_{z} z}^{b} Z^{b} & =K_{z}{ }^{b}
\end{aligned}
$$


Assume (xxii) holds with equality so innovation occurs in both blocs. Four of these equations, (xi), (xii), (xix) and (xxiii) refer to the world, the remaining 23 to each bloc. For the case where the credit constraint binds, this gives us $4+2 \times 23=50$ equations in total in endogenous variables $C_{z}^{b}, C_{y}^{b}, C_{m}^{b}, C^{b}, x^{b}, Y^{b}, Z^{b}, K_{y}^{b}, K_{z}^{b}, B_{y}^{b}, B_{m}^{b}, n^{b}, p_{m}^{b}, \pi^{b}, p_{z}^{b}$, $W^{b}, v^{b}, r^{b}, P^{b}, w_{L}^{b}, w_{H}^{b}, R_{y}^{b}, R_{z}^{b}, b=E, W$ and $p_{y}, P_{m}, \Lambda$ which total $23 \times 2+3=49$ variables. Where the credit constraint does not bind $r^{W}=r^{E}$ but we have one more endogenous variable $F^{W}$.

There appears to be too many equations. However our general equilibrium model describes an equilibrium in world traded output, and in non-traded output, the financial sector and labour markets in each bloc. By Walras' law we know one of the latter equilibrium conditions is in each bloc superfluous. If we eliminate one financial market relationship describing $A^{b}$ then we can dispense with equation (ix) reducing the equations by 4 and the variables by 2 . In fact, for the case of capital immobility with $B^{b}=0$ from (ix) and (x) and (xxii), a little algebra gives

$$
C^{b}+v^{b} \dot{n}^{b}+p_{y} \dot{K}_{y}^{b}+p_{z}^{b} \dot{K}_{z}^{b}=w_{L}^{b} L^{b}+w_{H}^{b} H^{b}+n^{b} \pi^{b}+\left(r^{b}+\delta\right)\left(p_{y} K_{y}^{b}+p_{z}^{b} K_{z}^{b}\right)
$$

which is a national income identity equating expenditure $\left(C^{b}\right)$ and investment in shares issued to finance new blue prints $\left(v^{b} n^{b}\right)$ plus investment in physical capital with labour income plus profits. Therefore, we can dispense with (ix) and (x). This leaves us with 46 equations in 47 endogenous variables - one equation short. However, there is nothing to pin down the price level in our model and we are free to choose any nominal variable as the numeraire.

\section{The Steady State}

Assume consumer preferences are identical in East and West. We also confine ourselves to the case of capital immobility (i.e, $\phi=0$ in (xi). We seek a balanced-growth steady state in which shares of manufacturing varieties $\xi^{b}=\frac{n^{b}}{n}$ are constant, the growth of varieties in the world produced by each bloc are equal and constant; i.e., $\dot{n} / n=\dot{n^{E}} / n^{E}=n^{W} / n^{W}=g$, all prices, wage rates, nominal consumption, nominal output and total nominal financial wealth $(n v)$ are all constant. Then we have $\dot{v}^{b} / v^{b}=-g ; b=E, W, \dot{P} / P=\theta_{m} g /(1-\epsilon)=$ 
$-\theta_{m} g(1-\alpha) / \alpha<0$ and $\Lambda=n / N$. Let $X^{b}=n^{b} x^{b}$ be manufacturing output ${ }^{9}$. Then the steady state takes the form

$$
\begin{aligned}
r & =\rho+\frac{1-\alpha}{\alpha} \theta_{m} g\left(\frac{1}{\sigma}-1\right) \\
A^{b} & =n^{b} v^{b}+p_{y} K^{b}+p_{z}^{b} K_{z}=N \xi^{b} \Gamma_{i}\left(\mathbf{w}^{b}, \mathbf{R}^{b}\right)\left(1-s^{b}\right)+p_{y} K_{y}^{b}+p_{z}^{b} K_{z}^{b} \\
p_{y} & =\Gamma_{y}^{E}\left(\mathbf{w}^{E}, \mathbf{R}^{E}\right)=\Gamma_{y}^{W}\left(\mathbf{w}^{W}, \mathbf{R}^{W}\right) \\
p_{m}^{b} & =\frac{1}{\alpha} \Gamma_{m}^{b}\left(\mathbf{w}^{b}, \mathbf{R}^{b}\right) \\
p_{y} Y^{b} & ={ }_{y} C^{b}+\delta p_{y} K_{y}^{b}+B_{y}^{b} \\
p_{z}^{b} Z^{b} & =\theta_{z} C^{b}+\delta p_{z}^{b} K_{z}^{b} \\
p_{m}^{b} X^{b} & =\theta_{m} C^{b}+B_{m}^{b} \\
B_{y}^{b}+B_{m}^{b} & =0 \\
R_{y}^{E}=R_{y}^{W} & =p_{y}(r+\delta) \\
R_{z}^{b} & =p_{z}^{b}(r+\delta) \\
r+g & =\frac{1-\alpha}{\alpha} \frac{\Gamma_{m}^{b}\left(\mathbf{w}^{b}, \mathbf{R}^{b}\right)}{\Gamma_{i}^{b}\left(\mathbf{w}^{b}, \mathbf{R}^{b}\right)\left(1-s^{b}\right)} X^{b} \\
L^{b} & =N \xi^{b} a_{L i}^{b}\left(\mathbf{w}^{b}, \mathbf{R}^{b}\right) g+a_{L m}^{b}\left(\mathbf{w}^{b}, \mathbf{R}^{b}\right) X+a_{L y}^{b}\left(\mathbf{w}^{b}, \mathbf{R}^{b}\right) Y^{b} \\
H^{b} & =N \xi^{b} a_{H i}^{b}\left(\mathbf{w}^{b}, \mathbf{R}^{b}\right) g+a_{H m}^{b}\left(\mathbf{w}^{b}, \mathbf{R}^{b}\right) X^{b}+a_{H y}^{b}\left(\mathbf{w}^{b}, \mathbf{R}^{b}\right) Y^{b} \\
K_{y}^{b} & =N \xi^{b} a_{K_{y} i}^{b}\left(\mathbf{w}^{b}, \mathbf{R}^{b}\right) g+a_{K_{y} m}^{b}\left(\mathbf{w}^{b}, \mathbf{R}^{b}\right) X^{b}+a_{K_{y} y}^{b}\left(\mathbf{w}^{b}, \mathbf{R}^{b}\right) Y^{b} \\
K_{z}^{b} & =N \xi^{b} a_{K_{z} i}^{b}\left(\mathbf{w}^{b}, \mathbf{R}^{b}\right) g+a_{K_{z} m}^{b}\left(\mathbf{w}^{b}, \mathbf{R}^{b}\right) X^{b}+a_{K_{z} y}^{b}\left(\mathbf{w}^{b}, \mathbf{R}^{b}\right) Y^{b} \\
\xi_{E}+\xi^{W} & =1
\end{aligned}
$$

giving 30 equations in 30 variables $g, r, R_{y}, p_{y}$ and $A^{b}, p_{m}^{b}, X^{b}, Y^{b}, K_{y}^{b}, K_{z}^{b}, B_{m}^{b}, B_{y}^{b}, \xi^{b}, C^{b}$, $R_{z}^{b}, \mathbf{w}^{b}=\left[w_{L}^{b}, w_{H}\right]^{b}, b=E, W$. We choose nominal GDP as the numeraire. Exogenous parameters driving the equilibrium are $\rho, \alpha, \sigma, \theta_{m}, \theta_{y}$ (describing the preferences of consumers), the depreciation rates $\delta$, technology parameters $T_{j}^{b}, \gamma_{k j}, \eta_{j}, \xi_{j} ; k=1,2, \cdots, 3$,

\footnotetext{
${ }^{9}$ As noted in Lundborg and Segerstrom (2000, 2002) individuals experience identical growth rates in consumer utility while utility levels can differ. This is because the two economies are connected by trade and consumers in both countries benefit from any new innovation. In the model we seek a balanced-growth steady-state in which the share of manufacturing varieties is constant, the growth of varieties in the world and in each bloc are equal and constant, all prices, wage rates etc. are all constant. In general, the conclusion that trade leads to one world growth rates relies on the assumption of international spill-overs. See Feenstra (1996) and Grossman and Helpman (2001) for details.
} 
$j=y, z, m, i$, for the four sectors of the traditional good, manufacturing and $\mathrm{R} \& \mathrm{D}$ and exogenous endowment proportions $L^{b}$ and $H^{b}$.

The additional relationship which is rendered superfluous by Walras' Law is

$$
C^{b}=r^{b} A^{b}+w_{L}^{b} L^{b}+w_{H}^{b} H^{b}-\xi^{b} \Gamma_{i}^{b}\left(\mathbf{w}^{b}, \mathbf{R}^{b}\right) s^{b}
$$

GDP is defined as value added in the R\&D sector $\left(\dot{n}^{b} v^{b}\right)$, plus that in the $\mathrm{m}, \mathrm{y}$ and $\mathrm{z}$ sectors: i.e., by

$$
\mathrm{GDP}^{b}=\xi^{b} \Gamma_{i}^{b} g+p_{m}^{b} X^{b}+p_{y} Y^{b}+p_{z}^{b} Z^{b}
$$

in the steady state. Define as proportions of nominal GDP $m^{b}=p_{m}^{b} X^{b} / G D P^{b}$ and similarly define $y^{b}$ and $z^{b}$ for bloc $b=E, W$. Define the R\&D and consumption shares as $r d^{b}=1-x^{b}-y^{b}-z^{b}=\Gamma_{i}^{b} \xi^{b} g / G D P^{b}$ and $c^{b}=C^{b} / G D P^{b}$ respectively. Define relative GDP as $r e l^{E}=G D P^{E} / G D P^{W}$. Then the steady state becomes:

$$
\begin{aligned}
& \frac{w_{L}^{b} a_{L i}^{b}}{\Gamma_{i}^{b}} r d^{b}+\frac{w_{L}^{b} a_{L m}^{b}}{p_{m}^{b}} m^{b}+\frac{w_{L}^{b} a_{L y}^{b}}{p_{y}} y^{b}+\frac{w_{L}^{b} a_{L z}^{b}}{p_{z}^{b}} z^{b}=\frac{w_{L}^{b} L^{b}}{G D P^{b}} \equiv{\text { wage } L^{b}}^{b} \\
& \frac{w_{H}^{b} a_{H i}^{b}}{\Gamma_{i}^{b}} r d^{b}+\frac{w_{H}^{b} a_{H m}^{b}}{p_{m}^{b}} m^{b}+\frac{w_{H}^{b} a_{H y}^{b}}{p_{y}} y^{b}+\frac{w_{H}^{b} a_{H z}^{b}}{p_{z}^{b}} z^{b}=\frac{w_{H}^{b} H^{b}}{G D P^{b}} \equiv \text { wage }^{b} \\
& \frac{a_{K_{y} i}^{b}}{\Gamma_{i}^{b}} r d^{b}+\frac{a_{K_{y} m}^{b}}{p_{m}^{b}} m^{b}+\frac{a_{K_{y} y}^{b}}{p_{y}} y^{b}+\frac{a_{K_{y} z}^{b}}{p_{z}^{b}} z^{b}=\frac{1}{\delta p_{y}}\left(y^{b}+m^{b}-\left(\theta_{m}+\theta_{y}\right) c^{b}\right) \\
& \frac{a_{K_{z} i}^{b}}{\Gamma_{i}^{b}} r d^{b}+\frac{a_{K_{z} m}^{b}}{p_{m}^{b}} m^{b}+\frac{a_{K_{z} y}^{b}}{p_{y}} y^{b}+\frac{a_{K_{z} z}^{b}}{p_{z}^{b}} z^{b}=\frac{1}{\delta p_{y}}\left(z^{b}-\theta_{z} c^{b}\right) \\
& \frac{r e l^{E} r d^{E}}{\Gamma_{i}^{E}}+\frac{r d^{W}}{\Gamma_{i}^{W}}=g \\
& r=\rho+\left(\frac{1}{\sigma}-1\right) \frac{\theta_{m} g}{\epsilon-1} \\
& R_{y}=p_{y}^{W}(r+\delta) \\
& R_{z}^{W}=p_{z}^{W}(r+\delta) \\
& R_{z}^{E}=p_{z}^{E}(r+\delta) \\
& \Gamma_{y}^{W}=\Gamma_{y}^{E} \\
& (r+g) r d^{W}=(1-\alpha) m^{W} g \\
& (r+g) r d^{E}=(1-\alpha) m^{E} g \\
& m^{W}+r e l^{E} m^{E}=\theta_{m}\left(c^{W}+r e l^{E} c^{E}\right) \\
& \frac{m^{W}}{m^{E}}=\frac{\Gamma_{i}^{E} r d^{W}}{\Gamma_{i}^{W} r d^{E}}\left(\frac{p_{m}^{W}}{p_{m}^{E}}\right)^{1-\epsilon}
\end{aligned}
$$


Noting that $p_{m}^{b}=\frac{\Gamma_{m}^{b}}{\alpha}, p_{y}=\Gamma_{y}^{b}$ and $p_{z}^{b}=\Gamma_{z}^{b}$, this gives us 18 equations in endogenous variables $x^{b}, y^{b}, z^{b}, c^{b}$, wage $L^{b}$, wage $^{b}, R_{z}^{b}(b=E, W), R_{y}, r, r e l^{E}$ and $g$. When there is no $\mathrm{R} \& \mathrm{D}$ in the East then $r d^{E}=x^{E}=0$. Nominal Western GDP is chosen as our numeraire.

\section{Immigration and Welfare}

We now turn to the balanced growth steady state of the full model as set above. Our calculations of the immigration surplus are based on pre- and post-migration equilibria and require distinguishing between the asset accumulation of migrants and the host country workers.

\subsection{Asset Accumulation following Migration}

At time t let $M_{l}(t), l=L, H$ be the numbers of Eastern households of type $l$ who have migrated in the post-migration state. Let $\bar{L}^{b}$ and $\bar{H}^{b}$ be the pre-migration levels of postmigration steady states of the two skill types. Then the working populations of the two skill types are given by

$$
\begin{aligned}
L^{E} & =\bar{L}^{E}-M_{L} ; L^{W}=\bar{L}^{W}+M_{L} \\
H^{E} & =\bar{H}^{E}-M_{H} ; H^{W}=\bar{H}^{W}+M_{H}
\end{aligned}
$$

We make no distinction between the worker of the same skill type in the two blocs. Nor do we allow for discrimination against immigrants in the Western labour market. As a consequence the only change on the supply side arises from the numbers of workers of each type. However the consumption/savings decisions of the migrants must be considered separately.

Following migration starts we need consider three residential groups of workers: migrants who have settled in the West; the remaining residents in the East and non-migrants in the West. We use a superscript $q=M, N, E$ to refer to these groups. Thus Western assets can now be divided into those held by the $\mathrm{M}$ and $\mathrm{N}$ groups; i.e., $A_{l}^{W}=A_{l}^{M}+A_{l}^{N}$ for each skill type $l=L, H$. Similarly consumption in the West by the l-type can be written

$C_{l}^{W}=C_{l}^{M}+C_{l}^{N}$. Assume that migrants accumulate their assets in the West. Aggregating over skill types as before and writing $A^{q}=A_{L}^{q}+A_{H}^{q}, q=M, N, E$ and $A^{b}=A_{L}^{b}+A_{H}^{b}$, and 
similarly for consumption, the household budget constraints for migrants, non-migrants in the West and remaining workers in the East are then given by

$$
\begin{aligned}
& \dot{A}^{M}=r^{W} A^{M}+w_{L}^{W} M_{L}+w_{H}^{W} M_{H}-T^{M}-C^{M} \\
& \dot{A}^{N}=r^{W} A^{N}+w_{L}^{W}\left(L^{W}-M_{L}\right)+w_{H}^{W}\left(H^{W}-M_{H}\right)-T^{N}-C^{N} \\
& \dot{A}^{E}=r^{E} A^{E}+w_{L}^{E} L^{E}+w_{H}^{E} H^{E}-T^{E}-C^{E}
\end{aligned}
$$

Aggregating (61) and (62) gives

$$
\dot{A}^{W}=r^{W} A^{W}+w_{L}^{W} L^{W}+w_{H}^{W} H^{W}-C^{W}
$$

where $T^{q}$ are taxes paid by group q. Thus, with our three assumptions - homogeneous labour of the same skill type between blocs, no discrimination against immigrants and migrants invest their assets with in the West - the budget constraints, consumption and savings decisions aggregate in a straightforward manner. The only economic effect on the aggregate economies arises from the change in working populations given by (60). However the welfare of our six groups need to be calculated separately and this requires that the assets of each group are carefully identified following migration from East to West.

Total assets in the West of which groups $q=N, M$ have some share are given by $\bar{A}^{W}=\bar{\xi}^{W} \bar{\Gamma}_{i}+\bar{p}_{y} \bar{K}_{y}{ }^{W}+\bar{p}_{z}^{W} \bar{K}_{z}{ }^{W}$ in the pre-migration state owned by the total premigration population and $A^{W}=\xi^{W} \Gamma_{i}+p_{y} K_{y}^{W}+p_{z}^{W} K_{z}^{W}$ after migration that increases the total Western population to $N^{W}=(1+M) \bar{N}^{W}$ where $M=\frac{M_{L}+M_{H}}{N^{W}}$ is the total migration rate. First consider the accumulation of the physical capital component of these assets. For the y-sector, after migration, in the new steady state $K_{y}^{W}-\bar{K}_{y}^{W}$ of capital accumulates which now has value $p_{y}\left(K_{y}^{W}-\bar{K}_{y}^{W}\right)$. Migrants don't bring capital with them, but do save and share in the newly accumulated capital and acquire $\frac{M}{1+M} p_{y}\left(K_{y}^{W}-\bar{K}^{W}\right)$ leaving non-migrants with their initial holding, now valued at $p_{y}$ and their share of the new capital, $\frac{1}{1+M} p_{y}\left(K^{W}-\bar{K}^{W}\right)$. Treating capital in the z-sector and equity similarly we arrive at the total assets of Western non-migrants and migrants as

$$
\begin{aligned}
A^{N} & =\frac{\Gamma_{i}\left(M \bar{\xi}^{W}+\xi^{W}\right)}{1+M}+\frac{p_{y}\left(M \bar{K}_{y}^{W}+K_{y}^{W}\right)}{1+M}+\frac{p_{z}^{W}\left(M \bar{K}_{z}^{W}+K_{z}^{W}\right)}{1+M} \\
A^{M} & =\frac{M \Gamma_{i}\left(\xi^{W}-\bar{\xi}^{W}\right)}{1+M}+\frac{M p_{y}\left(K_{y}^{W}-\bar{K}_{y}^{W}\right)}{1+M}+\frac{M p_{z}^{W}\left(K_{z}^{W}-\bar{K}_{z}^{W}\right)}{1+M}
\end{aligned}
$$

In the East remaining households own all the assets $A^{E}=\xi^{E} \Gamma_{i}^{E}+p_{y} K_{y}^{E}+p_{z}^{E} K_{z}^{E}$. 
Finally we need to divide assets between skilled and non-skilled households within categories $q=N, M, E$. We assume this division corresponds their labour income; i.e.,

$$
\bar{A}_{L}^{N}=\frac{\bar{w}_{L}^{W} \bar{L}^{W}}{\bar{w}_{L}^{W} \bar{L}^{W}+\bar{w}_{H}^{W} \bar{H}^{W}} \bar{A}^{N} ; \bar{A}_{H}^{N}=\frac{\bar{w}_{H}^{W} \bar{H}^{W}}{\bar{w}_{L}^{W} \bar{L}^{W}+\bar{w}_{H}^{W} \bar{H}^{W}} \bar{A}^{N}
$$

in the pre-migration state with an analogous division in the post-migration state. We have now determined holdings of assets for skilled and unskilled non-migrants in the West, migrants and non-migrants remaining in the East before and after migration. We now turn to the calculations of welfare for these six groups.

\subsection{Welfare Calculations}

Given steady state assets and labour income we can now determine total consumption of unskilled non-migrants from (62) in the pre-migration state as

$$
\bar{C}_{L}^{N}=\bar{r} \bar{A}_{L}^{N}+\bar{w} \bar{L}-T_{L}^{N}
$$

with obvious analogous expressions for the post-migration state, for skilled non-migrants and for the other four group, $q=M, E l=L, H$. We are now in a position to calculate the immigration surplus based on the change in utility following migration

The utility of non-migrants group of skill type $l=L, H$ is given by

$$
U_{l}^{N}(t)=\int_{t}^{\infty} e^{-\rho(\tau-t)}\left\{\frac{\left[\left(C_{m l}^{N}\right)^{\theta_{m}}\left(C_{y l}^{N}\right)^{\theta_{y}}\right]^{1-1 / \sigma}-1}{1-1 / \sigma}\right\} d \tau ; \quad \sum_{i=m, y} \theta_{i}=1, \sigma \neq 1 ;
$$

Consider $\mathrm{T}$ periods after migration and assume $\mathrm{T}$ is large enough for the model to have reached its new balanced-growth steady state. Then $\dot{n} / n=g$, its steady state value, or $n(t)=n(T) e^{g(t-T)}$ for $t>T$. Then the steady-state welfare is calculated as:

$$
\begin{aligned}
U_{l}^{N} & =\frac{1}{1-1 / \sigma}\left[\frac{\left(C_{l}^{N} / \tilde{P}\right)^{1-1 / \sigma} n(T)^{\theta_{m}(1-1 / \sigma) /(\varepsilon-1)}}{\rho-\theta(1-1 / \sigma) g /(\varepsilon-1)}-\frac{1}{\rho}\right] ; l=L, H \\
& =U_{l}^{N}\left(C_{l}^{N}, n(T), g\right)
\end{aligned}
$$

say, where $\tilde{P}^{b}=\left(\frac{p_{m}^{b}}{\theta_{m}^{b}}\right)^{\theta_{m}^{b}}\left(\frac{p_{y}^{b}}{\theta_{y}^{b}}\right)^{\theta_{y}^{b}}\left(\frac{p_{z}^{b}}{\theta_{z}^{b}}\right)^{\theta_{z}^{b}}$.

To calculate the welfare based immigration surplus we compare the utility before and after migration at the same pre-migration level of varieties, $n(T)=\bar{n}$, say. We measure this change in utility in terms of an equivalent permanent consumption change as follows. Let $\Delta U_{l}^{q}$ be change in utility coming about from a $1 \%$ permanent change in consumption 
at the pre-migration steady state at $n(T)=\bar{n}$ calculated by perturbing consumption in (67). Then using the notation indicated in the latter equation, the immigration surplus for the two types of worker, in terms of an equivalent \% change in utility, is obtained as

$$
\text { Immigration Surplus }=\frac{U_{l}^{N}\left(C_{l}^{N}, \bar{n}, g\right)-U_{l}^{N}\left(\bar{C}_{l}^{N}, \bar{n}, \bar{g}\right)}{\Delta U_{l}^{N}} ; l=L, H
$$

Note that this expression is independent of our choice of $\bar{n}$. Similarly we define the welfare gain in terms of equivalent permanent changes in consumption for the migrants and the remaining Eastern residents as

$$
\begin{aligned}
\text { Migration Surplus } & =\frac{U_{l}^{M}\left(C_{l}^{M}, \bar{n}, g\right)-U_{l}^{M}\left(\bar{C}_{l}^{M}, \bar{n}, \bar{g}\right)}{\Delta U_{l}^{M}} ; l=L, H \\
\text { Emigration Surplus } & =\frac{U_{l}^{E}\left(C_{l}^{N}, \bar{n}, g\right)-U_{l}^{E}\left(\bar{C}_{l}^{E}, \bar{n}, \bar{g}\right)}{\Delta U_{l}^{E}} ; l=L, H
\end{aligned}
$$

\section{Results}

The impact of migration in the host and in the receiving country is a result of counteracting forces. Some authors focus on the impact on wages and on labour market conditions in general as in Borjas (1995). Others, as Lundborg and Segerstrom (2000 and 2002) look at the negative impact on the asset value of equity issued to finance R\&D. Finally, other authors focus on the negative impact of migration on the terms of trade as in Davis and Weinstein (2002). In our general equilibrium framework the factors that contribute to the immigration/emigration surplus/deficit are: technological complementarities, terms of trade, change in asset prices, efficiency and sectoral reallocation effects. The mentioned static and dynamic effects have often a counteracting impact on the economic welfare at home and abroad. For this reason, we now turn to numerical solutions of the steady state using the calibrated parameter values set out in table 5. Refer to Appendix A for details on the calibration procedure. For a particular choice of TFP in the East we examine the effect of East-West migration with different skill compositions. Though all the effects are present in our simulations, by concentrating on migration with and without skill bias keeping the other parameters fixed, we focus our analysis on the efficiency and the sectoral reallocation effects of international migration. 


\subsection{East-West Migration}

In the next two sections we consider the case where the East is relatively less endowed with skilled labour with $L^{W}=H^{W}=0.25$, whereas $L^{E}=0.3$ and $H^{E}=0.2$. In addition TFP is less in the East and we put $T F P^{W}=1.75 T F P^{E}$.

\subsubsection{Migration with no Skill Bias}

Figures 1 and 2 shows the effect of a $10 \%$ increase in the Western population from immigration with no skill bias in its composition. An increase in growth now occurs of $0.25 \%$ which is almost entirely the result of a movement of workers from a country with a low TFP to one with a high TFP (the efficiency effect). All sectors in the West grow as they absorb the immigrant workers. The transfer of workers from a less to a more efficient R\&D sector sees the Western share of new products rise and world growth rises. The consequent increase in demand for high skill labour causes the relative skill-unskilled wage in both blocs to rise. There is a small rise in the Western R\&D share $r d^{W}$ and a small decrease'in $r d^{W}$.

The effect of these changes on welfare is summarised in figure 1, (b) to (e). Figure 1(e) shows the world surplus worked out as the equivalent \% permanent change in consumption for a representative household consisting of skilled and unskilled workers, East and West at weighted according to post-migration proportions. The maximum world surplus is around $9 \%$ when migration reaches $10 \%$ of the Western workforce. This breaks down into $1 \%$ for Western skilled workers, about $0.5 \%$ for native unskilled workers, giving an immigration surplus of around $0.85 \%$ for the representative Western native household (figure $1 \mathrm{~b}$ ). For those remaining in the East skilled workers gain by over $0.75 \%$, unskilled workers lose by $-1.35 \%$ giving an emigration deficit for the representative Eastern non-migrant of about $-1.2 \%$ (figure 1c). Finally figure 1(d) shows that the representative migrant gains by a substantial 200\%. In summary, with our parameter values, the positive efficiency effect comes to dominate the potential static negative effects highlighted in the literature.

\subsubsection{Migration with Skill Bias}

We now show the impact in our model of a $10 \%$ in the Western population from immigration with skill bias. A change in the composition of labour will have an impact on the 
way resources are allocated between the differen sectors (sectoral reallocation effect) with a positive or negative impact on growth depending on the type of migration we are considering. In this framework with biased migration, the manufacturing and R\&D sectors play an important role. Our next set of simulations in figures 3 and 4 look at the effect of a $10 \%$ increase in the Western population consisting of skilled workers. Now there are additional reallocation effects in both blocs arising from the changes in the proportions of skilled to unskilled workers. Taken together with the efficiency effect of a movement from a less to a more efficient economy, growth now rises by over $0.5 \%$ (figure $3 \mathrm{a}$ ). The world surplus now rises to $11 \%$ (figure 3e). The immigration surplus is almost $12 \%$ for unskilled natives, $-2.5 \%$ for skilled natives averaging at almost $6 \%$ (figure $3 \mathrm{~b}$ ). The emigration surplus is $17 \%$ for skilled, $-50 \%$ for unskilled averaging at $-10 \%$ (figure 3c), but both skilled and unskilled migrants gain substantially again (figure 3c). Finally, figure 4(f) shows the effect of high skilled migration on the terms of trade of the host country. Migration now has a negative impact on the terms of trade of Western countries. See Appendix B for details on the terms of trade. This result, in line with Davis and Weinstein (2002), shows that even with a negative terms of trade effect, which is part of our general equilibrium analysis, high skilled migration is beneficial for the economy ${ }^{10}$. Different results apply in case of unskilled migration. ${ }^{11}$.

We then look at the impact of a $10 \%$ increase in the Western population consisting of unskilled migration. As shown in Drinkwater et al. (2007) unskilled migration will have a negative impact on the world growth rate ${ }^{12}$. Respect to skilled migration, now we have a symmetrical sectoral reallocation effect due to a change in the opposite direction of the proportion of skilled and unskilled workers in the West, but there is still a positive efficiency effect due to a movement of workers from a country with a low TFP to one with a high TFP. The world surplus is now a modest $0.4 \%$. The emigration surplus is $13 \%$ for

\footnotetext{
${ }^{10}$ In this paper we only focus on Cobb-Douglas technologies, but in Drinkwater et al. (2007) we show that when skilled labour and capital are complements, the complementarity improves the impact of skilled migration

${ }^{11}$ see below

${ }^{12}$ In Drinkwater et al. (2007) we also investigate the impact of migration on the immigration surplus for different degree of complementarities and we show that when skilled labour and capital are complements changes in asset prices can have a significant effect and that the complementarity worsens the impact of unskilled migration.
} 
unskilled and $-12 \%$ for skilled while the immigration surplus is $5 \%$ for skilled natives and $-16 \%$ for unskilled natives. See figure 5 .

The main result that is emerging is that while unskilled migration can decrease growth, migration of no-skill bias and skilled migration from a low to a high TFP region of the world can increase growth, but in the absence of some distribution mechanism there are winners and losers, with remaining non-migrants in the latter category. The reason is that the East sees a reduction in its share of high tech goods which involve a price mark-up over marginal cost, and the relative wage of the unskilled workers fall. Indeed from figure $4 \mathrm{~b}$ skilled migration of over $5 \%$ of the West workforce sees the R\&D and high-tech sectors disappear altogether in the East.

One possible distribution mechanism is through remittance between migrants and their families remaining in the East. We then look at the effects of skilled migrants remitting a given percentage of their income ranging between $0 \%$ and $50 \%$. Assuming that families are either entirely skilled or unskilled, these remittances will end up in the pocket of skilled households in the East. This group were winners in the absence of remittances so remittances in themselves do not mitigate the distributional effects of migration. However if we assume that intra-country distributional mechanisms exist, or that households are of mixed skilled type, then we can focus on the representative household in both blocs. Then we can show that at any remittance rate above around $35 \%$, migrants remain substantial winners, and the Eastern representative household begins to emerge as a winner. These welfare effects with remittances are summarized in table 3 .

\begin{tabular}{|c|c|c|c|}
\hline Type of Migration & Growth Effect (\%) & IS (\%) & ES (\%) \\
\hline Unbiased & 0.3 & 0.85 & -1.2 \\
Skilled & 0.5 & 5.5 & -8.0 \\
Skilled with 50\% remittances & 0.5 & 5.5 & 7 \\
\hline
\end{tabular}

Table 3. Growth, Immigration Surplus (IS), Emigration Surplus (ES) of Representative Households. 


\section{Conclusions and Future Research}

This paper examines the impact of migration from a poor East to a rich West of different skill compositions where the East is characterized by a lower TFP and a lower skill-unskilled labour ratio calibrated to reproduce observed differences in the size of the traditional and high-tech sectors in a typical host and in a typical sending region. Our results may be summarised as follows

1. East-West migration induces two effects: an efficiency effect from the more efficient use of labour in the West and a sectoral reallocation effect arising from the change in the skilled-unskilled wage rates. The first effect is studied by examining migration with no skill bias and the second by examining migration of exclusively skilled labour.

2. Both types of migration result in a increase in world growth in the steady state. Skilled-labour migration results in a shift out of the high-tech sector in the East so that eventually at a level of migration over to $5 \%$ of the Western population that sector disappears altogether. Then Eastern specialization in traditional sectors occurs.

3. Despite growth gains there are winners and losers. With skilled migration, skilled households gain in the East and lose out in the West. The representative West household gains but its Eastern counterpart loses out. The overwhelming winner is the migrant herself. An important redistributive mechanism that can mitigate these distributional effects is the existence of remittances. In our simulations a remittance rate of around $35 \%$ still leaves the skilled migrant better of and sees the representative household in the East joining her counterpart in the West as a winner.

4. Unskilled migration, as expected, has a negative impact on the world growth rate due to the dominance of the now negative sectoral reallocation effect.

There are a number of ways in which the model presented here can be developed. First, we have assumed away labour market imperfections. There are many ways of modelling these: the search-matching approach to migration of Ortega (2000) is one promising direction to go. Second, fiscal instruments can be made available to the policy-maker such as a migrants' tax. Fourth, there are unexplored issues associated with the modelling of 
endogenous growth. The removal of scale effects can be handled in other ways (see, for example, Segerstrom (1998), Li (2000). We have restricted capital formation to traditional sectors for theoretical convenience. It is not obvious how to obtain balanced growth paths with constant prices if we allow for capital formation in the high-tech expanding sector and this needs to be investigated further. 


\section{A Calibration}

To relate the model to two typical host and sending economies, the first requirement of the exercise is to identify which types of labour relate to the categories of 'skilled' and unskilled' and which sectors constitute traditional, high-tech manufacturing and R\&D. We will assume identical consumer preferences for migrants and non-migrants.

To carry out the simulations the following parameter values are required:

Utility Weights, Elasticities and Discount Rates: $\theta_{m}, \theta_{y}, \theta_{z}, \sigma, \alpha$ and $\rho$. Capital Depreciation Rate: $\delta$.

Production Function Weights, Elasticities and Total Factor Productivities: $\gamma_{k j}, k=1,3 ; j=m, y, i, z, \quad \eta_{j}, \xi_{j}, j=m, y, i, z, \quad T_{j}, j=m, y, i, z$.

Pre-Migration unskilled and skilled labour proportions: $(\bar{L}, \bar{H})$

The procedure commonly referred to as the 'microeconomic approach' to calibration (see, for example the discussion in Shoven and Whalley (1992) chooses values for weights in utility and production functions to be consistent with observations of data in the form of averages of sector shares, factor shares within each sector, the real interest rate and the growth rate over a number of years. Elasticities in production are selected using econometric estimates. Our baseline calibration assumes Cobb-Douglas production technology. ${ }^{13}$

Then all the parameters are re-calibrated so that the steady state of the model is consistent with the original data. Notice we assume $\mu$ and $\eta$ are the same in all three sectors.

We use econometric estimates for $\sigma$ and $\delta$ and various sources on price mark-ups for $\alpha$. From table 5 the following are chosen: $\sigma=0.4, \delta=0.1$ and $\alpha=0.7$. Estimates of the depreciation rates lie around this value as reported in Canova (1994), Canova and Ortega (1996) and Canova and Ravn (2000). ${ }^{14}$

\footnotetext{
${ }^{13}$ Simulations with a generalized CES production function to investigate the case where skilled labour and capital are complements are presented in Drinkwater et al. (2007) for the one-country model. We remain faithful to the main result reached by the relevant literature in our choice of a Cobb-Douglas production function for the baseline calibration. From GTAP (Global Trade, Assistance and Production) where GTAP is a large computable general equilibrium model (see Hertel et al, 2001) estimates for the elasticity of substitution between skilled/unskilled and labour/capital, it seems clear that this parameter is close to 1 so that the production function can take approximately the Cobb-Douglas form. This functional form is often assumed in many aggregated studies.

${ }^{14}$ Estimates for the intertemporal elasticity of substitution were found in Ogaki and Reinhart (1998).
} 
We refer to Keuschnigg and Kohler (1999a) and Keuschnigg and Kohler (1999b) for the estimates of the preference of variety $\alpha$. The average mark-up in the high tech sector (Chemical, Trans. Equipment, etc.) is 1.13 where the mark-up is defined as $\frac{\epsilon}{\epsilon-1}=\frac{1}{\alpha}$. This implies that our parameter for the preference of variety, according to Kohler et al. estimates is $\alpha_{\text {Austria }}=0.8$. If we decide to include German data for the estimate of the mark-up in the high tech sector, we can refer to table 8 of the German case by the same authors. They give estimates of the mark-up in Chemicals and we refer to it as an industry representative of the high tech sector. The mark-up is 1.43. This gives us a value of $\alpha_{\text {Germany }}=0.68$. This leaves us with a weighted average value of $\alpha_{W e s t}=0.7$ (i.e. we take Austria and Germany as representative countries). The literature in general confirms a central value of $\alpha$ equal to 0.7 .

In the pre-migration equilibrium this leaves parameters $\left[T_{i}, \rho, \theta_{m},\left\{\gamma_{k j}\right\}, k=1,2 ; j=\right.$ $y, m, i, z]=\Theta$, say, to calibrate. Then $\theta_{y}=1-\theta_{m}$ completes the calibration.

On the production side, units of output and factor inputs can be chosen such that $T_{m}=T_{y}=T_{z}=1 .{ }^{15}$ Let $s_{L j}, s_{H j}$ be the factor shares of unskilled and skilled workers respectively in sector $j=i, m, y, z$ as evaluated in the balanced growth steady state of our model. Denote data for these shares by $\hat{s}_{L j}, \hat{s}_{H j}$. We obtain data for the technology parameters from Kohler et al. (1999) by aggregating the 29 sectors included in their economy. 16

Point estimates range from 0.32 to 0.45 and so we choose a value $\sigma=0.4$.

${ }^{15}$ We choose units of output, skilled and unskilled labour and capital such that $L_{j}=H_{j}=K_{j}=1$ results in one unit of output in sector $j=y, m, z$. Then in our constant returns to scale production function we have that $T_{j}=1$.

${ }^{16}$ They rely on Input/Output data for the Austrian economy complemented by auxiliary ones (e.g., the Industrial Characteristics Data). We refer to Table A.17 in Kohler et al., following an aggregation in line with the classification of Burda and Hunt (2001) for the following estimates of the factor shares $s_{i j} ; i=L, H, K ; j=y, m, i, z: s_{i j}=\sum_{\ell=1}^{n_{j}} s_{i j \ell} / n_{j} \mathrm{i}=\mathrm{L}, \mathrm{H}, \mathrm{K}$ and $\mathrm{j}=\mathrm{y}, \mathrm{m}, \mathrm{i}, \mathrm{z}$ where $\ell$ represents the industry in the $\mathrm{j}$ sector (i.e. farming, fishing, etc,) and $n_{j}$ the number of industries included in the aggregated $j$ sector.Traditional Traded: $s_{L y}=0.27$ as an average of the following numbers:

Farming $=0.462$ Fishing $=0.46$ Fuel Extracts $=0.12$ Mining $=0.23$ Food $=0.23$ Text $=0.39$ Leather $=0.27$ Wood $=0.26$ Paper $=0.22$ Manufacturing $=0.24$. Similarly, $s_{H y}=0.43$ is obtained as an average of: Farming $=0.482$ Fishing $=0.425$ Fuel Extracts $=0.24$ Mining $=0.33$ Food=0.47 Text=0.41 Leather $=0.50$ Wood $=0.45$ Paper $=0.50$ Manufacturing $=0.49$. Under this assumption, the share for capital in the traditional traded sector is equal to $s_{K y}=1-s_{L y}-s_{H y}=0.30 . s_{L m}=0.17$ is obtained as an average of: Chemical $=0.20$; Plastic $=0.32 ;$ Machines $=0.18 ;$ Electrics $=0.19 ;$ Transp. Equipment $=0.22 ;$ Finance $=0.05 ;$ Real Estate $=0.07 ;$ 
We also refer to Table A.17 in Keuschnigg and Kohler to obtain numerical values for the proportions of skilled and unskilled in the economy. The authors refer to the Austria Skill data set and the values are obtained by considering the arithmetic average of three different definitions of skilled and unskilled labour. ${ }^{17}$ Factor shares of skilled labour, unskilled labour and capital are reported as 48\%, 22\% and 30\% respectively. This is consistent with equal numbers of skilled and unskilled labour assumed in the baseline calibration if the skilled/unskilled wage ratio is $2.15: 1$, which is reasonable.

Let $\frac{\widehat{p_{m} X}}{p_{y} Y+p_{z} Z}$ be data for the relative nominal outputs in the manufacturing and traditional sectors respectively. To obtain estimates of the dimension of each sector, we look at the value added reported in Burda and Hunt (2001) in Table 10. ${ }^{18}$

As specified in Grossman and Helpman (1991), the high tech sector (i.e. electrical machinery, electronics, office machinery, chemicals, etc.) accounts for nearly of all spending on industrial R\&D in the OECD countries (OECD 1989). This implies that 1.05 of R\&D comes from the high tech Sector and the remaining 0.35 comes from the traditional sector (traded/non-traded). Other sources are OECD data which confirm a size of about $2 \%$ for R\&D. According to Parente and Prescott (2000) there is one category of investment expenditures which are not included in the national accounts, namely investments in intangible capital. We may consider including some of these investments as part of the R\&D sector. R\&D expenditures do not entirely consist of the costs of perfecting the new Health $=0.18$. In a similar way $s_{H m} s_{H z}$ and $s_{L z} s_{K m}$ and $s_{K z}$ are obtained.

R\&D: Referring again to tables in Keuschnigg and Kohler, assuming that the Education Sector is representative of the R\&D sector: $s_{L i}=0.076, s_{H i}=0.882, s_{K i}=0.042$

${ }^{17}$ Definition 1 : Individuals with apprenticeship level of education or lower are treated as unskilled, the remainder being treated as skilled labour. Definition 2 as before but individuals with apprenticeship are considered skilled. Definition 3: assistant and semi-trained workers are treated as unskilled.

${ }^{18}$ We choose West Germany (Berlin excluded) as a representative country for the West and look at the composition of value added with reference to 2000. Traditional: Agriculture and forestry=1.1; Trade/Eating and Drinking + Transportation=17.5; Low Tech Industry=10; Construction =4.3 ; Public and Private Services=19.8; Leasing and Business Services=10.7; Total Dimension = 64\% ((Traditional traded $=0.29 \%$ and Traditional untraded $=0.35 \%$ ). High Tech Manufacturing: High Tech Industry $=16 \%$; Banking and Finance $=20 \%$; Total Dimension $=\mathbf{3 6 \%}$. At the same time, we consider the R\&D sector. R\&D expenditures comes from Business + Government + Higher Education. Looking at Office for National Statistics data - for UK (1999), expenditure on R\&D are divided as: England: Business $=1.4$; Government $=0.2$; Higher Education (University) $=0.4$; Total Dimension $=$ $2 \%$. 
manufacturing processes and new products. In particular, we refer to the value of time engineers spend developing more efficient production methods, the time managers spend matching people with tasks (i.e. engineers with particular problems), as well as other similar activities (investment in organizational capital). It is difficult to determine the exact size, but Parente and Prescott guestimate that firms' investment in organizational capital may be around $12 \%$ of GDP and part of it can be included in the R\&D sector.

Similarly let data on the real interest rate, the long-term growth rate be denoted by $\hat{r}$ and $\hat{g}$ respectively. Given parameters $\Theta$, we can then solve for the balanced growth steady state with values $g(\Theta), r(\Theta), p_{m}(\Theta) X(\Theta), p_{y}(\Theta) Y(\Theta), p_{z}(\Theta) Z(\Theta), s_{L j}(\Theta), s_{H j}(\Theta)$, $j=i, m, y, z$. Given data for these variables we can then solve

$$
\begin{aligned}
g(\Theta) & =\hat{g} \\
r(\Theta) & =\hat{r} \\
s_{L j}(\Theta) & =\hat{s}_{L j} ; j=i, m, y \\
s_{H j}(\Theta) & =\hat{s}_{H j} ; j=i, m, y \\
\frac{p_{m}(\Theta) X(\Theta)}{p_{y}(\Theta) Y(\Theta)+p_{z}(\Theta) Z(\Theta)} & =\frac{\widehat{p_{m} X}}{p_{y} Y+p_{z} Z}
\end{aligned}
$$

\begin{tabular}{|c|c|c|}
\hline Data & Value & Source \\
\hline$\hat{r}$ & 0.03 & stylized \\
$\hat{g}$ & 0.07 & stylized \\
$p_{m} X$ & 0.36 & Burda and Hunt (2001) \\
$p_{y} Y$ & 0.29 & Burda and Hunt (2001) \\
$p_{z} Z$ & 0.35 & Burda and Hunt (2001) \\
$s_{L y}$ & 0.27 & Keuschnigg and Kohler (1999a, 1999b) \\
$s_{H y}$ & 0.43 & Keuschnigg and Kohler (1999a, 1999b) \\
$s_{L m}$ & 0.17 & Keuschnigg and Kohler (1999a, 1999b) \\
$s_{H m}$ & 0.50 & Keuschnigg and Kohler (1999a, 1999b) \\
$s_{L i}$ & 0.076 & Keuschnigg and Kohler (1999a, 1999b) \\
$s_{H i}$ & 0.882 & Keuschnigg and Kohler (1999a, 1999b) \\
\hline
\end{tabular}

Table 4. Data used in Calibration

For data, we choose $\hat{r}=0.03$ and $\hat{g}=0.06$. Since all growth in our model is concentrated 
in the manufacturing sector of size $\theta_{m}$, this gives long-term GDP growth as $\theta_{m} \hat{g}=2.2 \%$ in our calibration. Table 5 summarizes the baseline calibration.

In our results the size of the R\&D sector is around $5 \%$. Previously, we review estimates of the size of the $R \& D$ which suggest a value around only $2 \%$. However some R\&D must be contained within unobserved 'intangible' investment (Parente and Prescott (2000)). The size of actual as opposed to observed R\&D in our model is therefore not implausible. Note also that our simulations show a skilled/unskilled wage ratio of 2:1 which is reasonable, given the broad definition of 'skilled' labour that makes it half the working population ${ }^{19}$.

\begin{tabular}{|c|c|c|}
\hline Parameter & Value & Source \\
\hline $\bar{H}$ & 0.5 & Keuschnigg-Kohler (1999a, 1999b) \\
$\bar{L}$ & 0.5 & ditto \\
$\sigma$ & 0.4 & Ogaki and Reinhart (1998) \\
$\alpha$ & 0.7 & Keuschnigg-Kohler (1999a, 1999b) \\
$\delta$ & 0.1 & Canova and Ortega (1996) \\
$\mu_{j}, \eta_{j}$, & 0.0 (i.e., Cobb-Douglas) & Camermesh (1993), GTAP \\
$T_{i}$ & 2.4 & Calibrated \\
$\rho$ & 0.01 & Calibrated \\
$\theta_{m}$ & 0.46 & Calibrated \\
$\gamma_{k y} ; k=1,2$ & $\gamma_{1 y}=s_{L y}=0.27, \gamma_{2 y}=s_{H y}=0.43$ & Calibrated \\
$\gamma_{k m} ; k=1,2$ & $\gamma_{1 m}=s_{L m}=0.17, \gamma_{2 m}=s_{H m}=0.50$ & Calibrated \\
$\gamma_{k i} ; k=1,2$ & $\gamma_{1 i}=s_{L i}=0.076, \gamma_{2 i}=s_{H i}=0.882$ & \\
\hline
\end{tabular}

Table 5. Summary of Baseline Calibration

\section{B Terms of trade}

On the terms of trade, first consider a price index of traded goods:

$$
P_{T}^{b}=\left(p_{m}^{b}\right)^{w_{b}}\left(p_{y}\right)^{1-w_{b}} ; b=E, W
$$

where

$$
w_{b}=\frac{\theta_{m}^{b}}{\theta_{m}^{b}+\theta_{y}^{b}}
$$

\footnotetext{
${ }^{19} \gamma_{2 y}=s_{H y}, \gamma_{1 y}=s_{L y}$, etc. Also $\gamma_{3 y}=\gamma_{4 y}$ and the same for the other sectors.
} 
Now define the terms of trade in the West as

$$
\tau^{W} \equiv \frac{P_{T}^{E}}{P_{T}^{W}}=\frac{\left(p_{m}^{E}\right)^{w_{E}}\left(p_{y}\right)^{1-w_{E}}}{\left(p_{m}^{W}\right)^{w_{W}}\left(p_{y}\right)^{1-w_{W}}}
$$

and $\tau^{E} \equiv \frac{1}{\tau^{W}}$. Hence if $w_{E}=w_{W}=w$, say, which we assume in our calibration, then the terms of trade simply become

$$
\tau^{W}=\left(\frac{p_{m}^{E}}{p_{m}^{W}}\right)^{w}
$$

and therefore the price of the traditional traded goods have no impact on the terms of trade. If preference parameters differ this is no longer the case.

\section{Stability and Transitional Dynamics (NOT FOR PUBLI- CATION)}

In the paper we have studied the balanced-growth steady state of the model. The full dynamic model has transitional dynamics and could in principle be unstable in the vicinity of the steady state. This section uses WINSOLVE ${ }^{20}$ to confirms numerically, for central parameter values, that the model is indeed saddle-path stable and examines the speed of convergence towards the steady state. Figures 6 to 11 show the dynamic adjustment of various endogenous variables of interest as the Western population jumps by $10 \%$ from immigration with no skill bias. We assume $T F P^{W} / T F P^{E}=1.75, L^{W}=H^{W}=0.25$ and $L^{E}=0.30 H^{E}=0.20$. With this assumption, we are in a position to make a comparison with the balanced-growth steady state reported in the paper.

Figure 6 (figure 6-11 are not for publication, but available from the authors) shows the effect of migration on the growth rate. ${ }^{21}$ In the figure, we report the pre-migration and post-migration values plus the dynamic adjustment. As verified in section 6 , the growth rate increases as a result of migration from a country with a low TFP to one with a high TFP. The growth rate (a forward-looking variable) jumps and overshoots the new steady-state value and then slowly converges the the steady-state value at the maximum migration level. It takes about 5 years to reach and then overshoot the steady state.

\footnotetext{
${ }^{20} \mathrm{~A}$ program written by Richard Pierce for solving and simulating nonlinear models

${ }^{21}$ Pre- and post-migration growth rates are denoted by gpre ss and gpost ss respectively. Growth in year $\mathrm{t}, g(t)$ is denoted by g dyn. Similarly for other variables.
} 
Figures 7 to 9 describe the effect of migration with no skill bias on sector shares. As shown in the paper, now the West diverts resources from the traditional to the manufacturing sector while the sector shares for the East have an opposite shift. Sector adjustment is plausibly slow: it takes about 20 years for the sector shares to achieve half of its eventual adjustment to the new steady-state value in the West. Adjustment is slower in the East. The reason for this is seen from figure 10 describing the transitional dynamics for the relative skilled-unskilled wage ratio in the two blocs. Relative wages adjust almost completely in the West after 10 years, at which time the East has not yet completed half its long-run adjustment.

Finally, figure 11 shows the transitional dynamic for the share of new products. As shown previously, Western new product share increases and the dynamic adjustment (which by definition is symmetric between blocs) takes about 20 years to complete half the long-run adjustment. Overall, this exercise confirms that the full dynamic model is stable in the vicinity of the steady-state. Growth adjusts more quickly than sector shares. The reason for this result lies in the forward-looking and labour-intensive nature of the R\&D sector. This causes growth, driven by $R \& D$, to respond quickly; output in the manufacturing and traditional sectors requires physical capital investment and adjusts more slowly. The larger R\&D sector in the West then sees relative wages and therefore sector shares changing more rapidly in that bloc (figure 11). 


\section{References}

Barro, R. and Sala-I-Martin, X. (1995). Economic Growth. McGraw-Hill International Editions, singapore.

Ben-Gad, M. (2003). Importing human capital: Immigration in the endogenous growth model. mimeo, University of Haifa.

Borjas, G. (1995). The economic benefits from immigration. Journal of Economic Literature, $\mathbf{9}(2), 3-22$.

Bretscher, L. (2001). Labour supply, migration, and long term development. Open economies review, 12, 5-27.

Bretschger, L. and Steger, T. (2004). The dynamics of economic integration: Theory and policy. Economic working paper, WIF Institute of Economic Research.

Burda, M. and Hunt, J. (2001). From reunification to economic integration: Productivity and the labour market in Eastern Germany. Brooking Papers on Economic Activity, 2, $1-92$.

Canova, F. and Ortega, E. (1996). Testing calibrated general equilibrium models. Simulation Based Inference in Econometrics: Methods and Applications, Mariano R. Schuermann and Weeks M. (eds).

Chui, M., Levine, P., Murshed, S., and Pearlman, J. (2002). North-South models of growth and trade: Survey and synthesis. Journal of Economic Surveys, 16, 1-43.

D'Auria, F. and Morrow, K. M. (2008). Economic impact of migration flows following the2004 enlargement process: A model based analysis, european economy. Economic Papers 349, European Commission, Brussels.

Davis, D. and Weinstein, D. (2002). Technological superiority and the losses from migration. Working Paper 8971, NBER.

Drinkwater, S., Levine, P., Lotti, E., and Pearlman, J. (2007). The immigration surplus revisited in a general equilibrium model with endogenous growth. Journal of Regional Science, 47(3), 569-601. 
Drinkwater, S., Levine, P., and Lotti, E. (2009). Labour market and Investment Effects of Remittances in Development Economics: Essays in memory of Anita Ghatak. Routledge Studies in Development Economics, Singapore.

Feenstra, R. (1996). Trade and uneven growth. Journal of Development Economics, 49, 229-256.

Felbermayr, G. and Kohler, W. (2007). Immigration and native welfare. International Economic Review, 48(3), 731-760.

Grossman, G. and Helpman, E. (2001). Innovation and Growth in the Global Economy. MIT Press, Cambridge, Massachusetts., 7th edition.

Hamermesh, D. (1993). Labor Demand. Princeton University Press, Princeton.

Hertel, T., McDougall, R., and Itakura (2001). GTAP model version 6.0. Centre for Global Analysis, www.gtap.agecon.purdue.edu.

Kahanec, M., Zaiceva, A., and Zimmermann, K. (2009). Lessons from migration after eu enlargement. Working Paper 4230, IZA.

Keuschnigg, C. and Kohler, W. (1999a). Eastern Enlargment to the EU: Economic costs and benefit for the EU present member states? The case of Austria. Final report, University of Linz. PART I and II.

Keuschnigg, C. and Kohler, W. (1999b). Eastern Enlargment to the EU: Economic costs and benefit for the EU present member states? The case of Germany. Final report, University of Linz.

Li, C. W. (2000). Endogenous vs semi-endogenous growth in a two-R\&D-sector model. The Economic Journal, 110, 109-122.

Lucas, R. J. (1988). On the mechanism of economic development. Journal of Monetary Economics, 22, 3-42.

Lundborg, P. and Segerstrom, P. (2002). The growth and welfare effects of international mass migration. Journal of International Economics, 56, 177-204. 
Lundborg, P. and Segerstrom, P. S. (2000). International migration and growth in developed countries: A theoretical analysis. Economica, 67, 579-604.

Ogaki, M. and Reinhart, C. M. (1998). Measuring intertemporal substitution: The role of durable goods. Journal of Political Economy, pages 1078-1098.

Ortega, J. (2000). Pareto-improving immigration in an economy with equilibrium unemployment. The Economic Journal, pages 92-112.

Parente, S. L. and Prescott, E. C. (2000). Barriers to Riches. MIT Press, Cambridge, Massachusetts. London, England.

Romer, P. (1990). Endogenous technical change. Journal of Political Economy, 98, S71S102.

Segerstrom, P. S. (1998). Endogenous growth without scale effects. American Economic Review, pages 1290-1310.

Shoven, J. and Whalley, J. (1992). Applying General Equilibrium. Cambridge University Press, Cambridge, USA.

Walz, U. (1995). Growth (rate) effects of migration. Zeitschrift fur Wirtschrift-u. Sozialwissenschaften, 115, 199-221. 


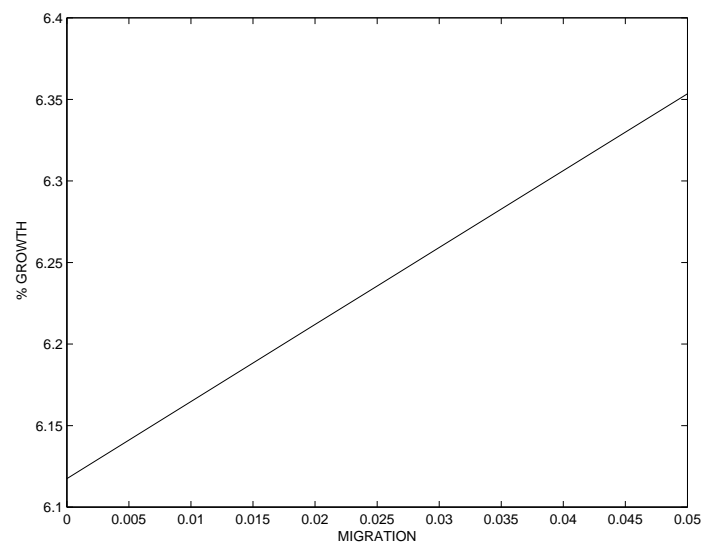

(a) WORLD GROWTH

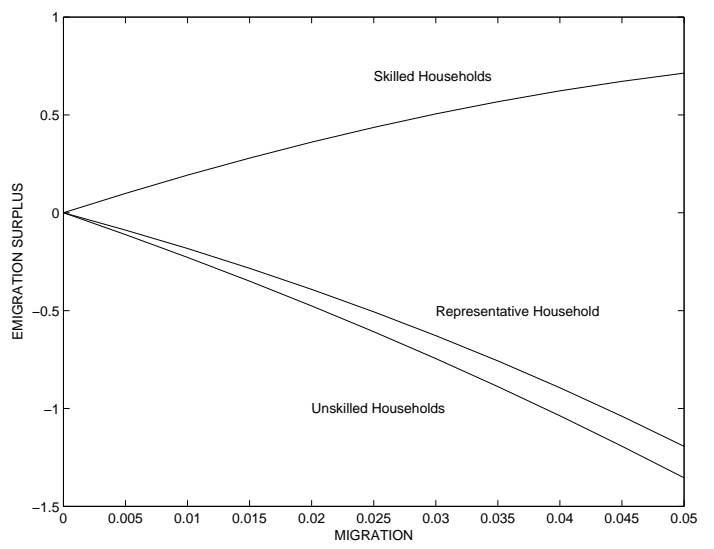

(c) EMIGRATION SURPLUS

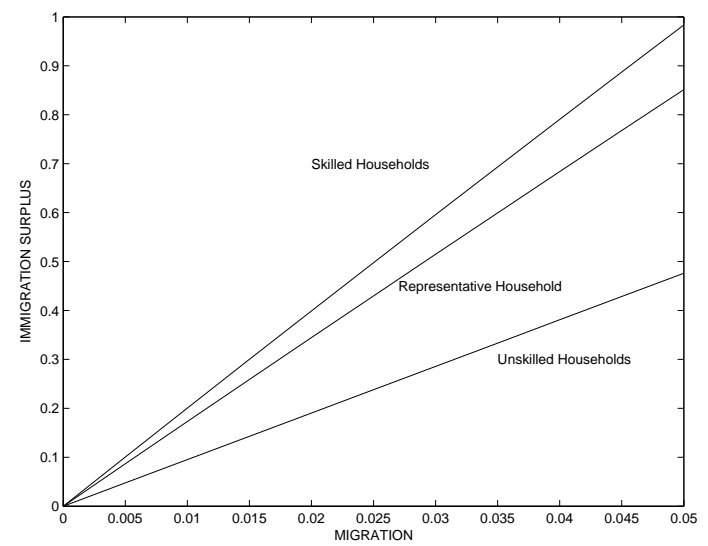

(b) IMMIGRATION SURPLUS

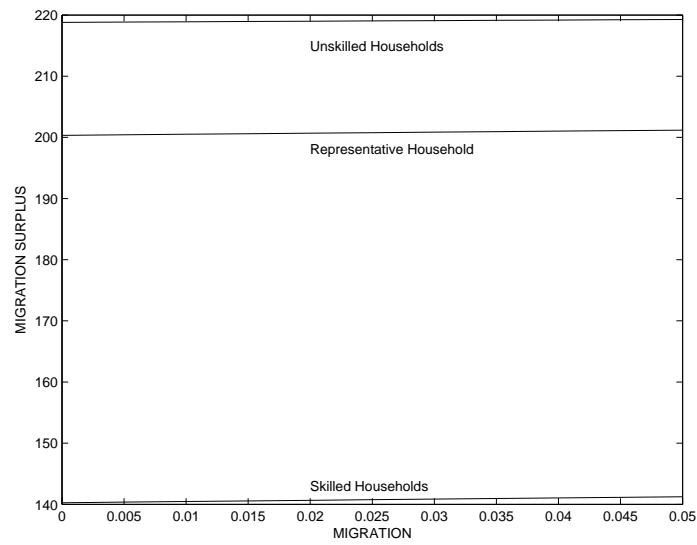

(d) MIGRATION SURPLUS

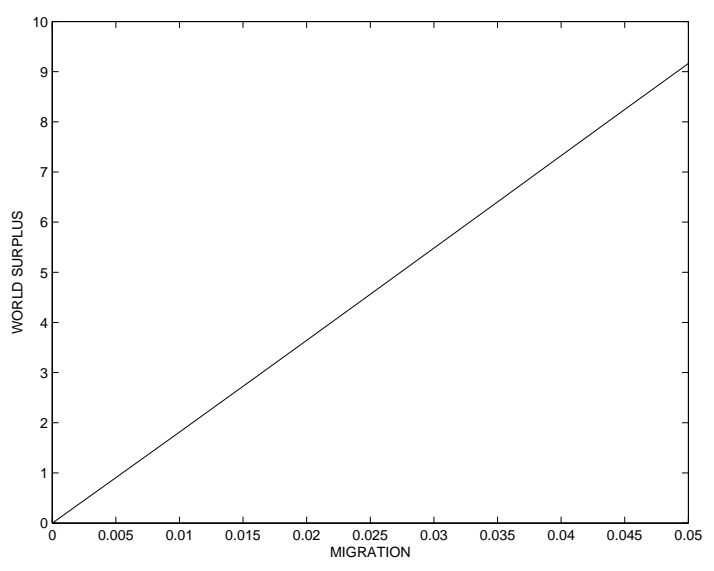

(e) WORLD SURPLUS

Figure 1: No-Skill bias migration with Pre-Migration Labour: $H^{E}=0.20 ; L^{E}=$ $0.30 ; H^{W}=L^{W}=0.25 ; T F P^{E}=1.75 T F P^{W}$ 


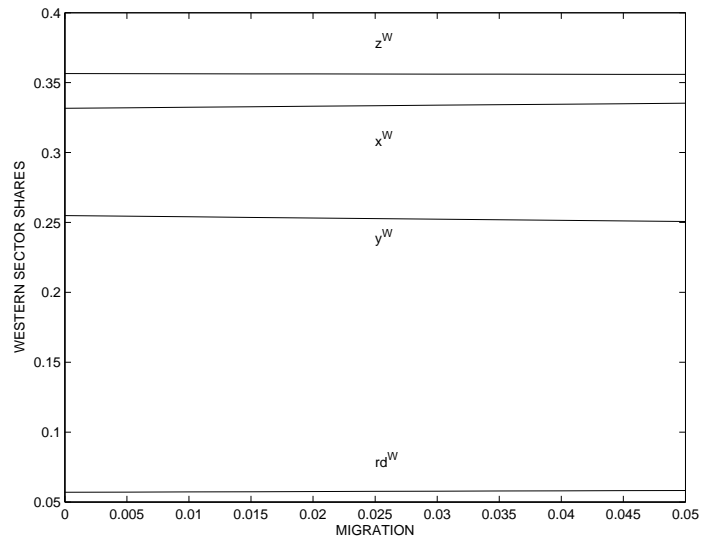

(a) WESTERN SECTOR SHARES

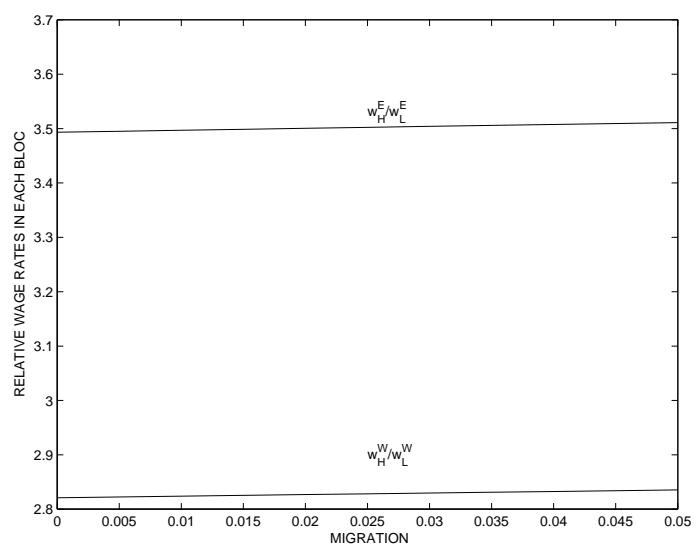

(c) RELATIVE WAGE RATES

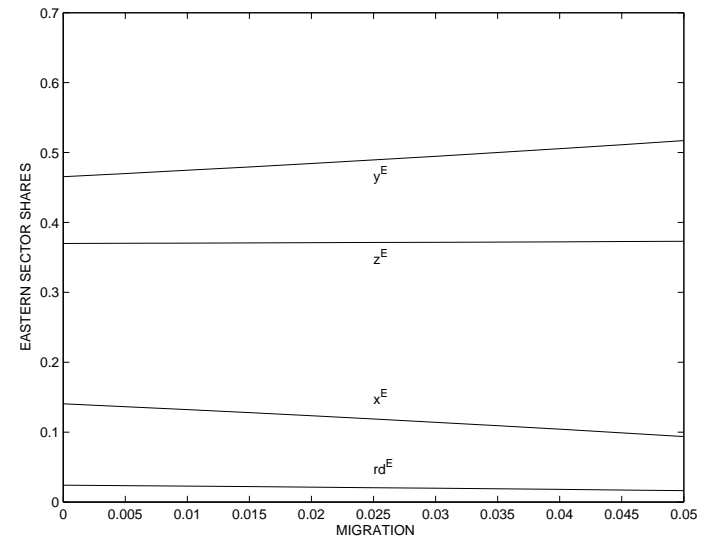

(b) EASTERN SECTOR SHARES

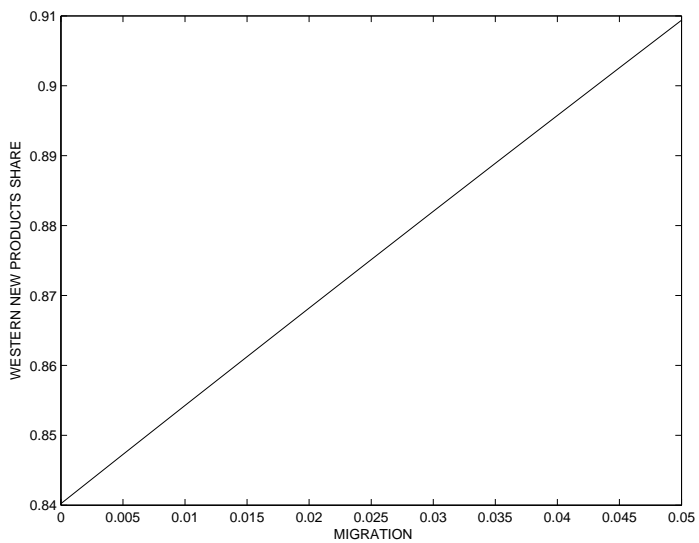

(d) WESTERN NEW PRODUCTS SHARE

Figure 2: No-Skill bias Migration with Pre-Migration Labour: $H^{E}=0.20 ; L^{E}=$ $0.30 ; H^{W}=L^{W}=0.25 ; T F P^{E}=1.75 T F P^{W}$ 


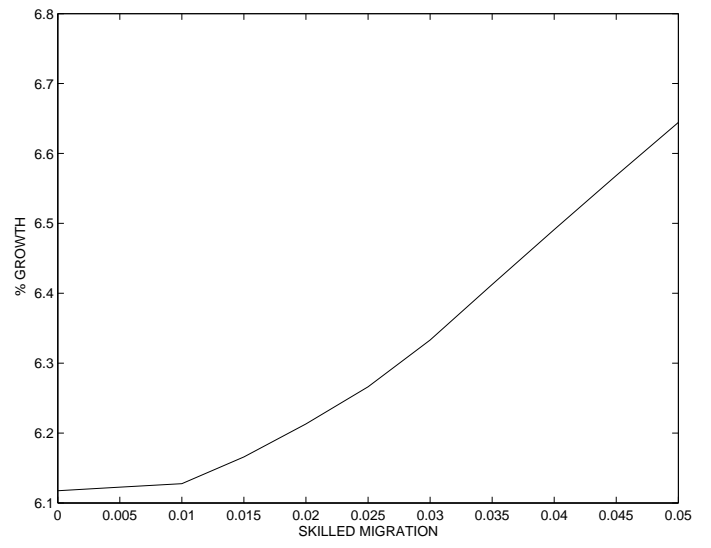

(a) WORLD GROWTH

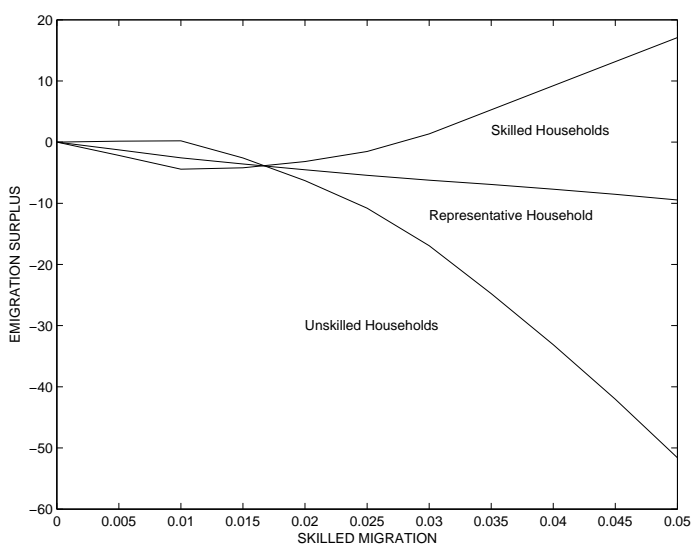

(c) EMIGRATION SURPLUS

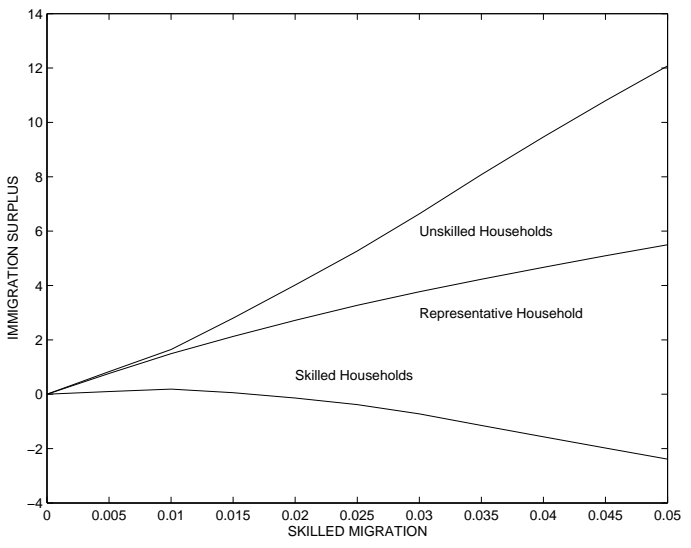

(b) IMMIGRATION SURPLUS

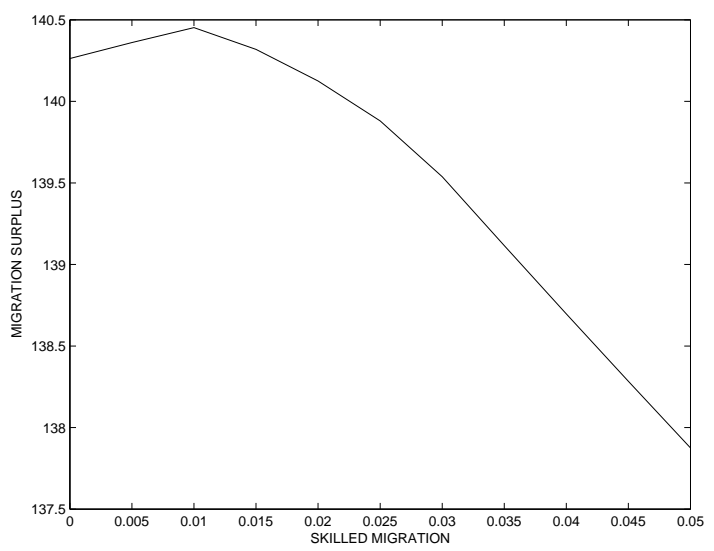

(d) MIGRATION SURPLUS

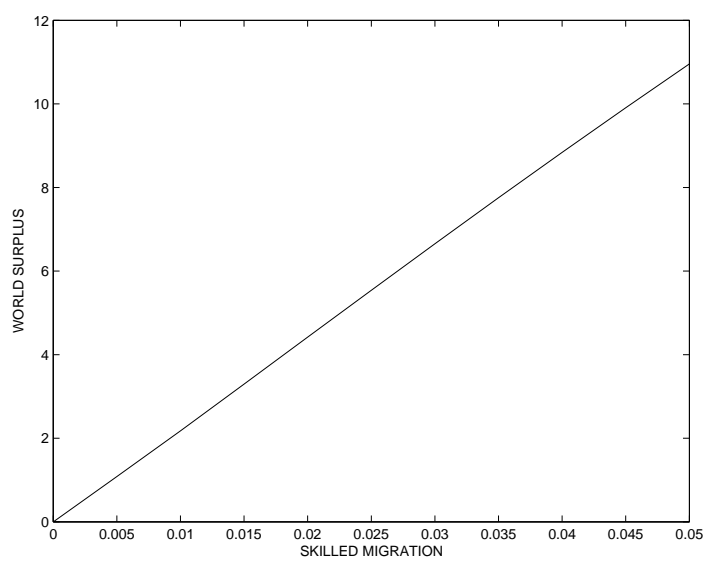

(e) WORLD SURPLUS

Figure 3: High Skilled Migration with Pre-Migration Labour: $H^{E}=0.20 ; L^{E}=$ $0.30 ; H^{W}=L^{W}=0.25 ; T F P^{E}=1.75 T F P^{W}$ 


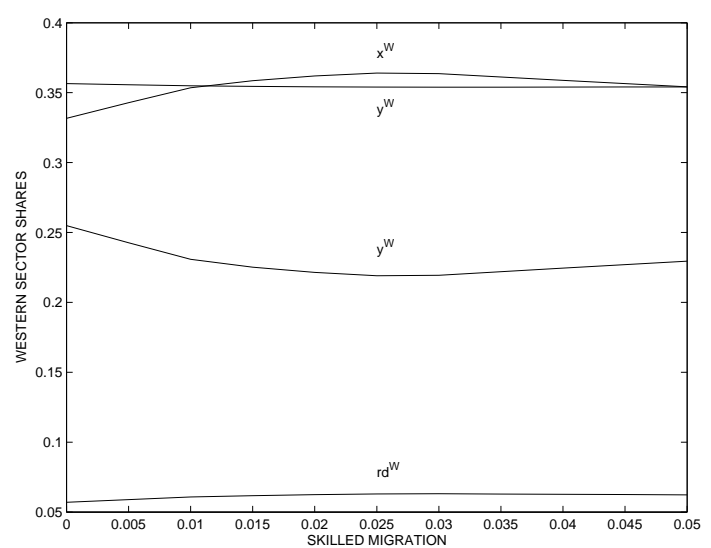

(a) WESTERN SECTOR SHARES

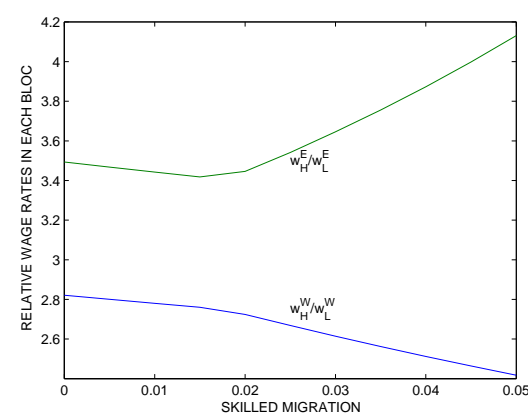

(c) RELATIVE WAGE RATES

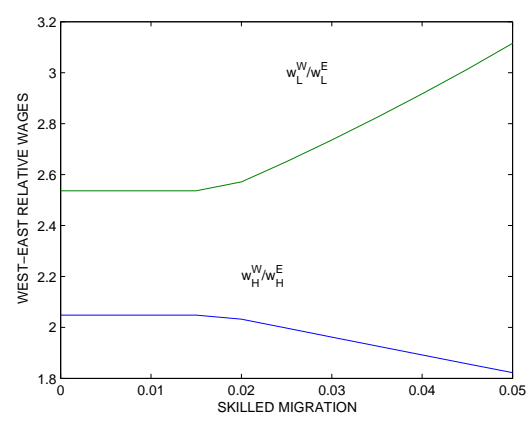

(e) MIGRATION PRESSURE

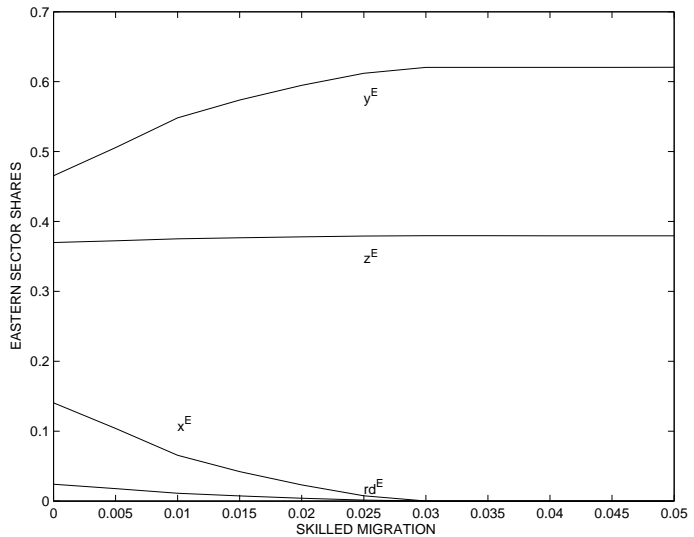

(b) EASTERN SECTOR SHARES

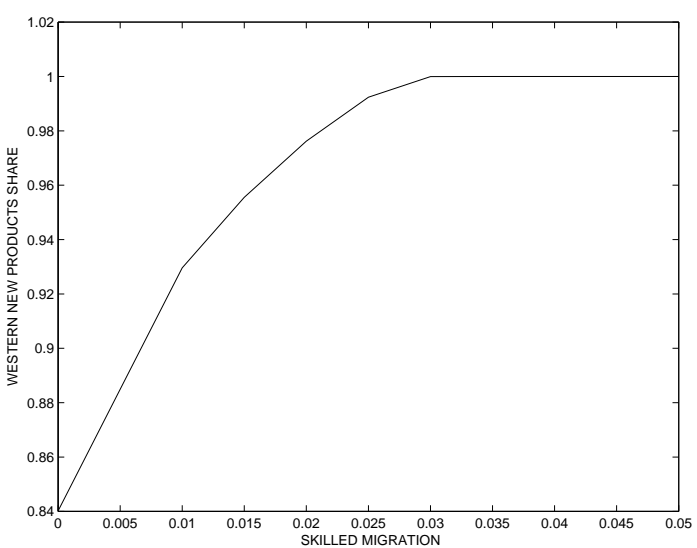

(ג) IXTLCTEDN NTEIT DDONTTCT CU A DEC

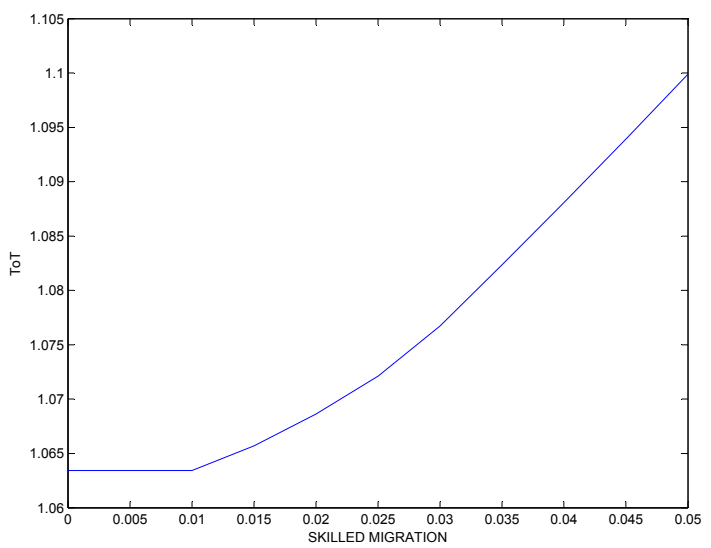

(f) TERMS OF TRADE

Figure 4: High Skilled Migration with Pre-Migration Labour: $H^{E}=0.20 ; L^{E}=$ $0.30 ; H^{W}=L^{W}=0.25 ; T F P^{E}=1.75 T F P^{W}$ 


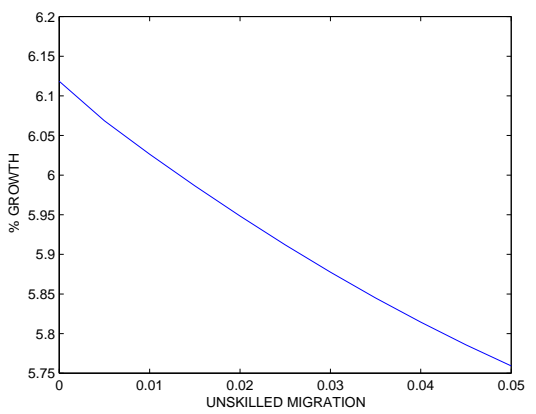

(a) WORLD GROWTH

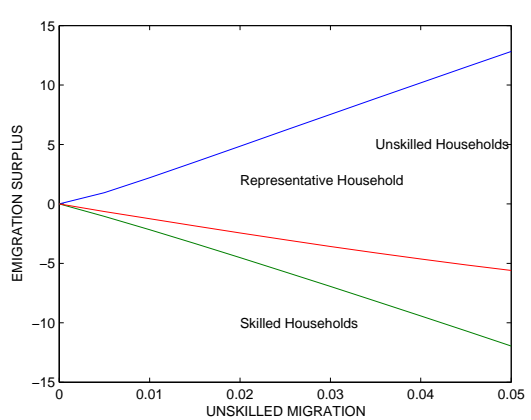

(c) EMIGRATION SURPLUS

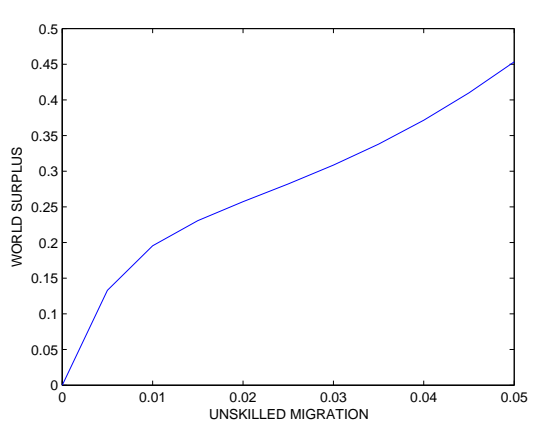

(e) WORLD SURPLUS

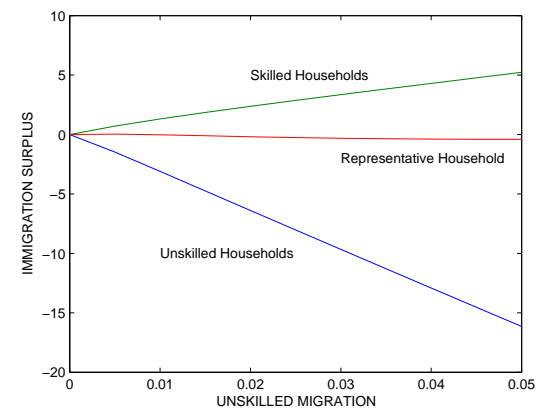

(b) IMMIGRATION SURPLUS

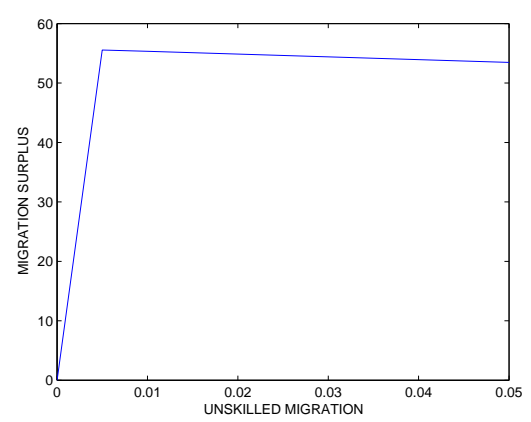

(d) MIGRATION SURPLUS

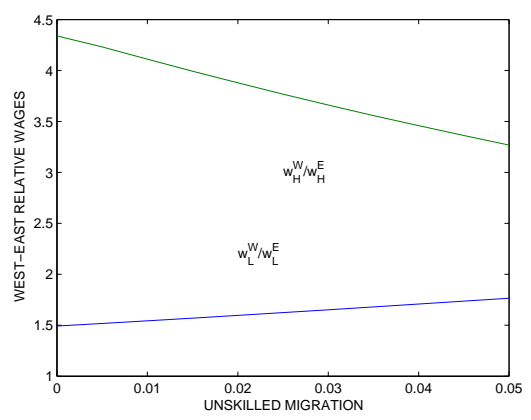

(f) MIGRATION PRESSURE

Figure 5: Low Skilled Migration with Pre-Migration Labour: $H^{E}=0.20 ; L^{E}=$ $0.30 ; H^{W}=L^{W}=0.25 ; T F P^{E}=1.75 T F P^{W}$ 


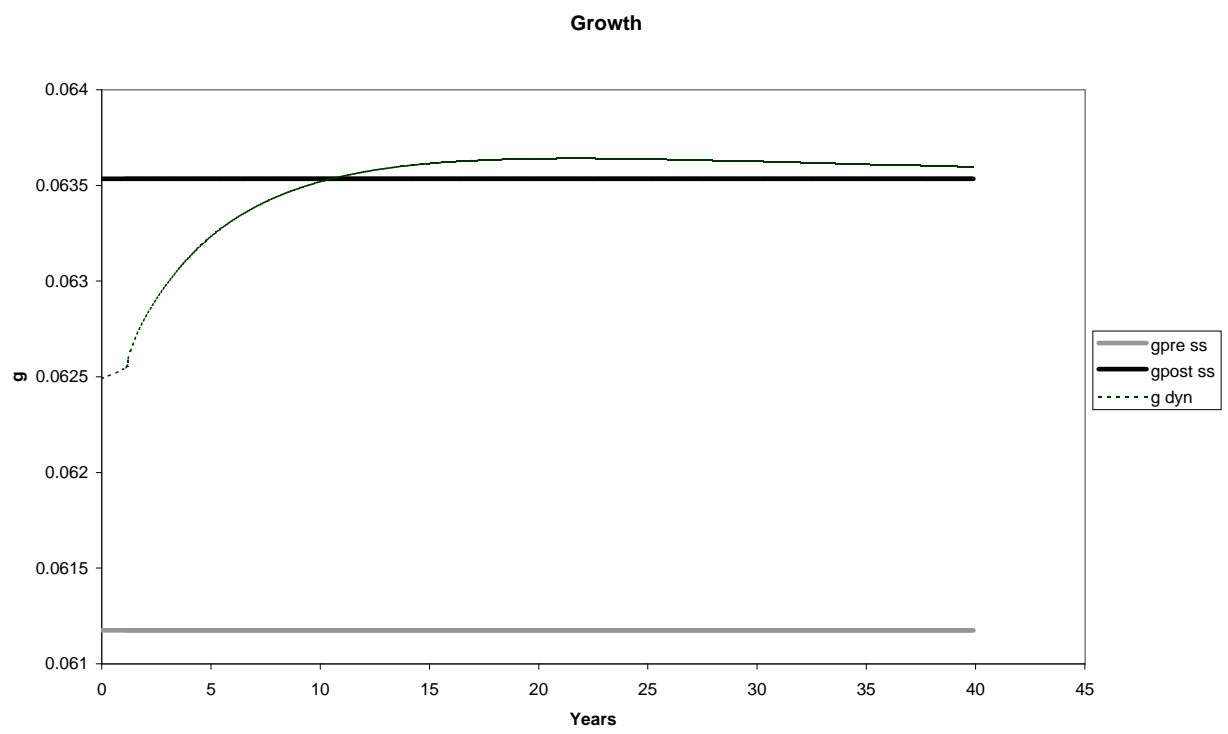

Figure 6: NOT for PUBLICATION Dynamic Simulation for Average Growth $g(t)$

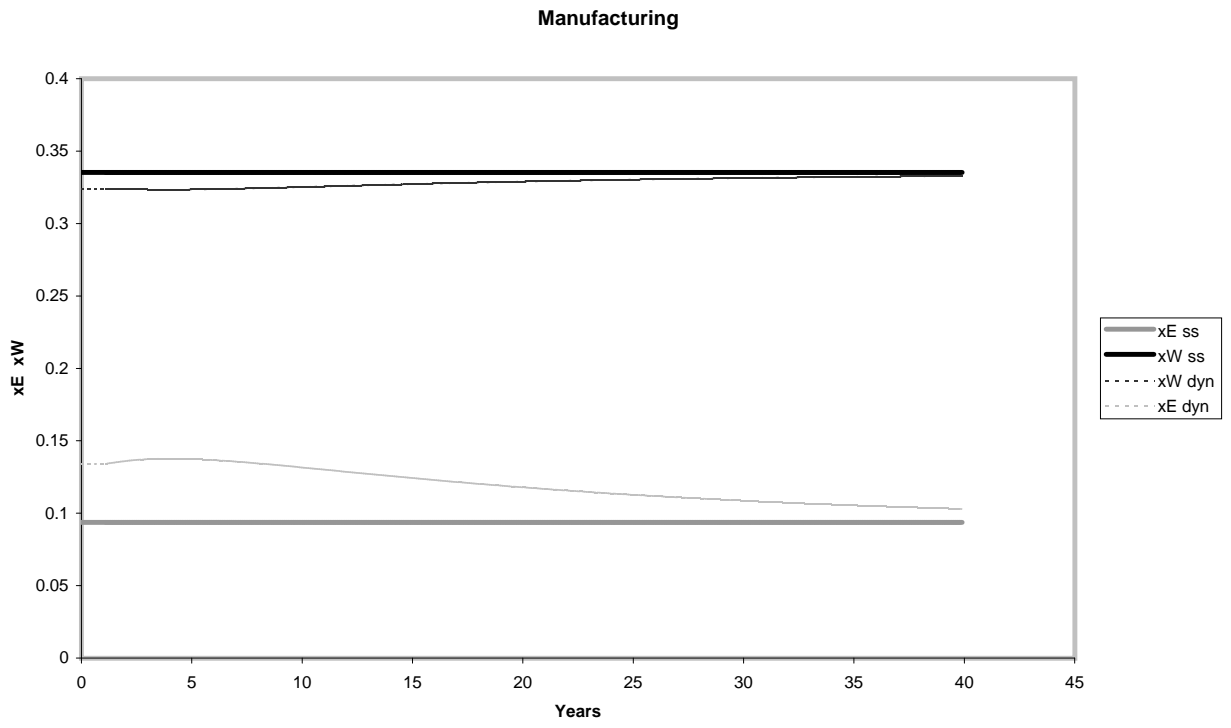

Figure 7: NOT for PUBLICATION Dynamic Simulation for East and West Manufacturing $x^{E}(t)$ and $x^{W}(t) . \quad 44$ 
Traditional traded

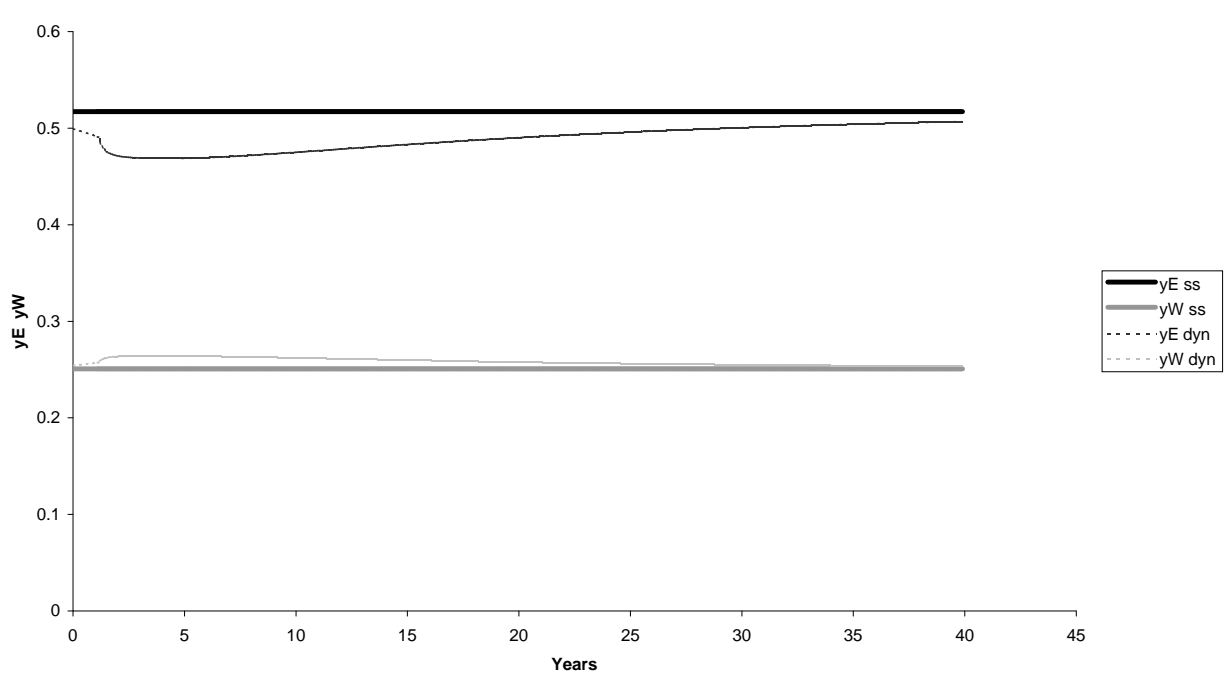

Figure 8: NOT for PUBLICATION Dynamic Simulation for East and West traditional traded sectors

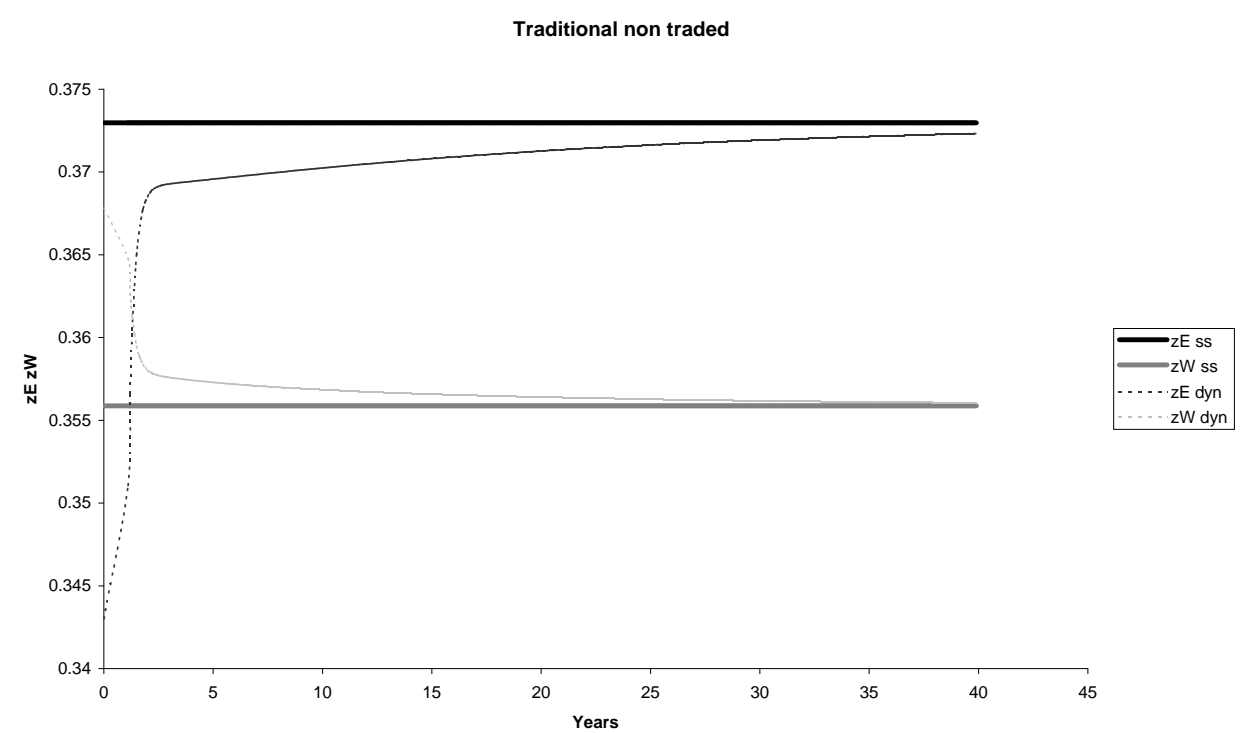

Figure 9: NOT for PUBLICATION Dynamic Simulation for East and West traditional non-traded sectors 


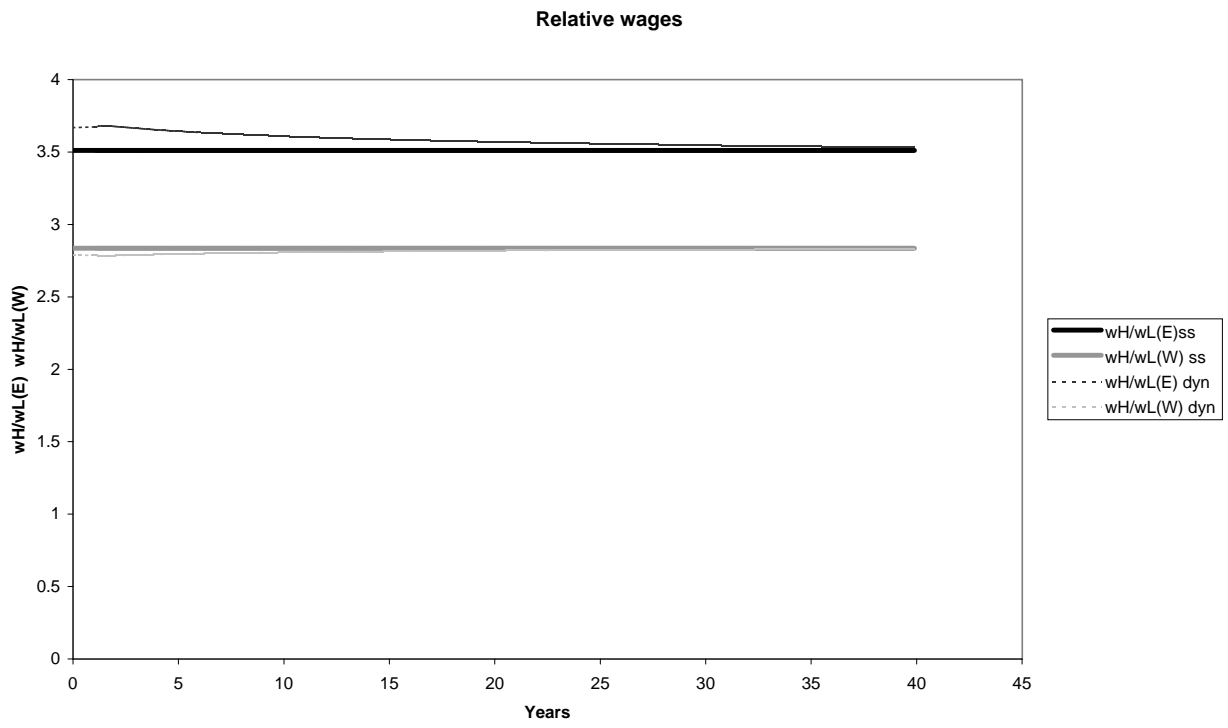

Figure 10: NOT for PUBLICATION Dynamic Simulation for East and West Wage Ratios

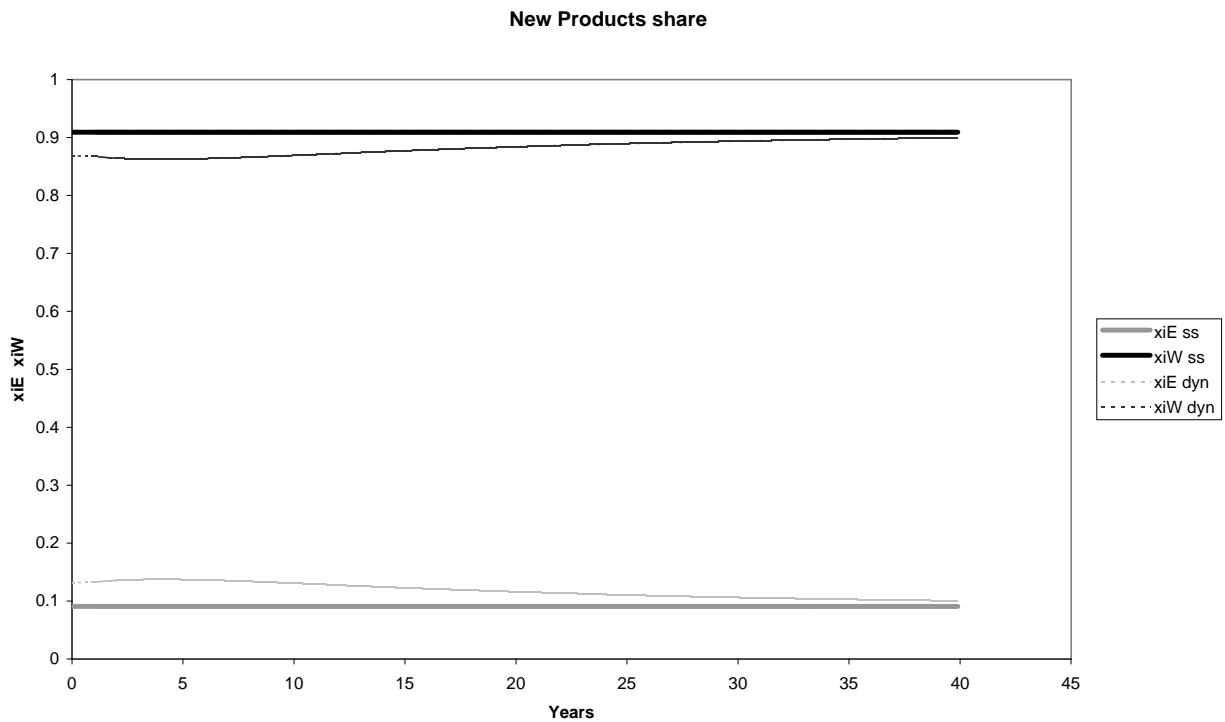

Figure 11: NOT for PUBLICATION Dynamic Simulation for East and West 